Ann. Biol. anim. Bioch. Biophys., I972, 12 (2), 243-262.

\title{
DÉPÔT ADIPEUX MÉSENTÉRIQUE DU PORGELET ÉTUDE MORPHOLOGIQUE
}

\author{
N. VODOVAR, F. DESNOYERS et J. FLANZY \\ avec la collaboration technique de S DELPAL \\ Station de Recherches de Nutrition, \\ Centre national de Recherches zootechniques, I. N.R. A., \\ 78 - Jouy-en-Josas

\section{RÉSTTMÉ}

L'organisation et l'évolution des préadipocytes et des adipocytes mésentériques ont été étudiées chez les porcelets au moment de la naissance et pendant les quarante-cinq premiers jours. Jusqu'à l'âge d'une semaine environ, les cellules adipeuses sont disséminées entre les feuillets mésentériques dans la partie du mésentère adjacente à l'intestin. L'apparition et l'emplacement de ces cellules sont étroitement liés à la prolifération et à l'orientation des capillaires sanguins.

Vers l'âge de sept jours, on observe l'apparition d'agrégats de cellules adipeuses; leur principale caractéristique est le mode de disposition des préadipocytes et des adipocytes autour des capillaires sanguins. Le mécanisme d'accroissement des agrégats de cellules adipeuses et l'édification du dépôt mésentérique, qui apparaît aux environs du dixième jour après la naissance, ont été observés. Les transformations structurale et ultrastructurale des préadipocytes et des adipocytes au cours de la formation et de la croissance du dépôt adipeux ont été décrites et discutées.

\section{INTRODUCTION}

Pendant un siècle, depuis les travaux de Tol,DT (ToL,or, I870) et de FLEMING (FLEMING, I87I), l'étude en microscopie optique a fourni de précieux renseignements sur les dépôts adipeux. Ces études morphologiques ont été malheureusement très limitées par les difficultés techniques de la préparation des coupes de tissu adipeux et surtout par la résolution insuffisante du microscope optique. Ce dernier problème, essentiel pour l'étude de l'évolution de la cellule adipeuse, a été en partie résolu par l'apparition de la microscopie électronique.

En I960, les travaux en microscopie électronique, comme le constate BARRNETT 
(BARRNETT, I96I), ont été au nombre de cinq pour les tissus à graisse brune et de quatre pour ceux à graisse blanche.

$\mathrm{Si}$ on se réfère à la littérature actuelle, on constate que les recherches relatives aux différents aspects des tissus adipeux en microscopie électronique au cours des dix dernières années, ne dépassent pas une trentaine de travaux alors que, pour la même période, ceux de biochimie atteignent plusieurs milliers. Les observations faites concernent surtout les tissus à graisse brune tandis que les tissus à graisse blanche, bien plus abondants et presque seuls chez la plupart des espèces domestiques et chez 1'Homme, n'ont été que très peu étudiés et on remarque également que la plupart des travaux sur les tissus adipeux à graisse blanche concernent, soit leur aspect fonctionnel (BARRNETT, BAI,L, I960 ; WASSERMANN, MCDONALD, I96o $a$, I $960 \mathrm{~b}$, I963), soit des points particuliers limités à un stade donné de leur évolution (ChASE, I959 $a$, I959 $b$; Simon, I962, I965 ; SHELDON, I965, I969).

En travaillant sur le dépôt adipeux épididymaire du Rat âgé d'une semaine, NAPOLITANo (NAPOLITANo, I963, I965 $a$, I965 $b$ ) est pratiquement le seul à avoir étudié les étapes successives de l'évolution des cellules adipeuses à graisse blanche au cours de l'accumulation des lipides. Ce nombre réduit de travaux en microscopie électronique sur les tissus adipeux à graisse blanche doit être attribué au fait que la confection des coupes ultrafines avec préservation des lipides est très délicate. Quoi qu'il en soit, on doit convenir, en tenant compte de la diversité des dépôts adipeux suivant leur emplacement et suivant les espèces, que nos connaissances actuelles sont très limitées, aussi bien en ce qui concerne l'origine, la prolifération et l'évolution des cellules adipeuses, qu'en ce qui concerne la formation et la croissance de ces multiples dépôts. D'autre part, il est certain que le progrès des études physiologiques et biochimiques des tissus adipeux normaux et pathologiques est étroitement lié aux connaissances structurales et ultrastructurales de ces dépôts.

De brèves observations préliminaires sur le mésentère du porcelet avant et après la naissance (Vodovar, SERRES, FRANçors, I969), ont montré la présence de préadipocytes et d'adipocytes disséminés entre les feuillets mésentériques à partir des quelques jours qui précèdent la naissance, tandis que des agrégats de cellules inégalement remplies de lipides apparaissent seulement vers la fin de la première semaine après la naissance.

La provenance des préadipocytes mésentériques et leur évolution au cours de l'accumulation des lipides chez le fœtus du Porc ont été étudiées récemment (VodoVAR, Desnoyers, FrançoIs, I97I). Les présentes observations concernent l'étape postnatale chez cette espèce, de la naissance au quarante-cinquième jour. On observera la formation des agrégats de cellules adipeuses, la constitution du dépôt et sa croissance ainsi que les transformations structurale et ultrastructurale des préadipocytes jusqu'au stade d'adipocytes. L'évolution des cellules adipeuses au cours de cette dernière étape sera étudiée.

Pour éviter les confusions souvent rencontrées dans la littérature, précisons que le terme d'adipocytes concerne les cellules adipeuses à partir du moment où les inclusions lipidiques ont fusionné en une seule masse de lipides. L,e terme de préadipocytes concerne toutes les autres cellules aux différents stades de l'accumulation des lipides et les cellules sans lipides considérées comme futurs adipocytes. Le terme de cellule adipeuse désigne l'adipocyte et le préadipocyte ayant déjà des inclusions lipidiques. 


\section{MATÉRIEL ET MÉTHODES}

Le mésentère des porcelets a été prélevé à la naissance, puis toutes les 24 heures après jusqu'à l'âge de dix jours et tous les cinq jours jusqu'à l'âge de quarante-cinq jours.

La fixation avec le tétroxyde d'osmium à 2 p. Ioo dans le tampon phosphate à o, I M (MilloNIG, 196I) est faite, soit directement, soit après séjour des tissus pendant deux à trois heures dans le glutaraldéhyde à $3,6 \mathrm{p}$. Ioo préalablement neutralisé à $\mathrm{pH} 7$ par le carbonate de sođium. Dans le premier cas, les animaux, sous anesthésie, sont ouverts ventralement et le fixateur est déposé sur le mésentère in situ pendant cinq à dix minutes. Par la suite, le mésentère extirpé a été coupé en petits fragments, orientés du bord libre au bord pariétal et laissés dans le fixateur pendant un temps variant de une à douze heures à $4^{\circ} \mathrm{C}$. La fixation prolongée avec renouvellement de fixateur semble permettre une meilleure conservation des lipides et l'obtention de meilleures coupes sans que la structure en soit détériorée. Les tissus ayant d'abord séjourné dans le glutaraldéhyde ont été postfixés avec le tétroxyde d'osmium par le même mode de fixation.

Les fragments de tissu, après fixation et rinçage dans le tampon phosphate, ont été déshydratés dans l'acétone avec un bref passage dans l'acétone à Ioo p. roo. L'inclusion a été faite, soit dans le mélange d'Épon 8I 2 (LUFT, I96I), soit dans le Vestopal (Napolitano, I963). Une partie des inclusions dans l'Épon est polymérisée à $37^{\circ} \mathrm{C}$ pour essayer de diminuer la diffusion des lipides, qui se produit à la température de $60^{\circ}$, température habituelle de polymérisation. Les blocs polymérisés à $37^{\circ} \mathrm{C}$ sont suffisamment durs pour être coupés au couteau de diamant et la préservation des lipides nous paraît meilleure. Les coupes obtenues avec l'Ultratome LKB III à une épaisseur de 500 à $700 \AA$ sont, dans la plupart des cas, ondulés au niveau des lipides où la dureté du bloc est moindre. Il en est de même en ce qui concerne les coupes semifines préparées pour l'observation de la taille des cellules par la méthode stéréologique.

Les coupes contrastées sur grille avec l'acétate d'uranyle to à zo minutes et avec le citrate de plomb pendant 5 minutes (REYNOLDS, 1963) ont été observées au Siemens Elmiscop IA.

\section{OBSERVATIONS}

\section{A. - Adipocytes et préadipocytes mésentériques à la naissance}

A la naissance du porcelet, les adipocytes polymorphes et les préadipocytes, aux différentes étapes de leur évolution, sont disséminés entre les feuillets mésentériques dans la partie du mésentère qui borde l'intestin (fig. I). A ce niveau, emplacement du dépôt adipeux mésentérique du Porc, les éléments vasculaires et nerveux sont abondants, les éléments du tissu conjonctif et notamment les fibres sans orientation précise, sont présents en quantités variables suivant le niveau. Quel que soit le stade de nos observations, on note l'absence totale de mastocytes chez cette espèce.

Les préadipocytes et les adipocytes, tout en étant séparés les uns des autres, sont, dans la plupart des cas, comme avant la naissance, répartis en petits groupes de trois à cinq cellules, parfois davantage (fig. 2). Ces petites unités, éléments de base du futur dépôt adipeux, éparpillées entre les feuillets mésentériques, présentent une topographie en rapport direct avec l'emplacement des capillaires sanguins. A l'apparition de chaque capillaire, dont la prolifération à cet âge et à ce niveau est très importante, on observe que des cellules endothéliales se séparent de la paroi vasculaire en formation ; elles restent à proximité des capillaires ou à leur contact et continuent leur évolution, se remplissent de lipides et deviennent adipocytes. 
L'emplacement des préadipocytes et des adipocytes à la naissance, leur structure et leur ultrastructure, en particulier la présence régulière d'une lame basale, sont semblables à ce que nous avons observé chez le fœtus (Vodovar, Desnoyers, FrançoIs, I97I).

\section{B. - Formation et croissance du dépôt adipeux mésentérique}

\section{Formation des agrégats de cellules adipeuses (schéma I).}

De jour en jour, après la naissance, le nombre de nouvelles unités de cellules augmente rapidement; leur emplacement se situe entre les unités existantes et la périphérie, vers le bord pariétal du mésentère. Par ailleurs, chaque unité croît pour son propre compte par augmentation simultanée du nombre et du volume des préadipocytes et des adipocytes.

Au fur et à mesure que le nombre et le volume des préadipocytes et des adipocytes augmentent, les espaces, tant entre cellules d'une même unité qu'entre les cellules et la paroi des capillaires, diminuent progressivement. Le terme final de cette évolution est la formation d'agrégats dont les cellules contiennent des inclusions lipidiques en quantité variable (fig. 3 ). Les premiers agrégats dans le mésentère du porcelet s'observent généralement à partir du septième jour après la naissance, très exceptionnellement avant.

La principale caractéristique à ce stade nous paraît être le fait que chaque préadipocyte ou adipocyte d'un agrégat demeure à proximité directe sinon au contact de la paroi d'un capillaire au moins (fig. 4).

\section{2. Édification et croissance du dépôt adipeux.}

Entre le septième et le dixième jour après la naissance, les agrégats de cellules inégalement remplies de lipides, en devenant très nombreux, parviennent à être très proches les uns des autres, sinon en contact (schéma 2). A ce stade, les cellules adipeuses d'un agrégat sont, par une partie de leur surface, à proximité immédiate d'un capillaire ou en contact avec lui ; sur le reste de leur pourtour elles sont entourées par des cellules adipeuses du même agrégat ou d'agrégats adjacents. De ce fait, et suivant 1'incidence des coupes, les capillaires peuvent parfois paraître absents, mais ce n'est qu'une apparence. Dès ce moment, on peut consirer que ces agrégats de cellules adipeuses font partie d'un ensemble qui représente le dépôt mésentérique (fig. 5).

Au premier stade de sa formation, l'architecture du dépôt adipeux mésentérique est relativement simple du fait que la juxtaposition des agrégats de cellules adipeuses se situe, sauf exception, dans un seul plan, qui est celui du mésentère (schéma 3). Ainsi, une couche assez uniforme d'agrégats est disposée entre les feuillets mésentériques en bordure de l'intestin. Cette relative simplicité de l'organisation du dépôt adipeux mésentérique semble pouvoir être attribuée à l'orientation du système microcirculatoire. En effet, les capillaires sanguins, origine des préadipocytes comme cela a été établi chez le fotus et autour desquels se forment les agrégats de cellules adipeuses, restent dans le plan du mésentère aussi longtemps qu'il existe des emplacements libres entre les feuillets mésentériques.

Dix jours environ après la naissance, on peut considérer que le dépôt adipeux 
mésentérique est réellement formé mais que, chez des animaux du même âge, son importance quantitative varie individuellement. Ces variations grossièrement appréciées en tenant compte de la surface et, éventuellement, de l'épaisseur du dépôt, ne semblent pas obligatoirement suivre la variation de poids des animaux.

Au cours des quarante-cinq jours qui suivent la naissance, l'édification, puis l'accroissement du dépôt adipeux semblent, dans les cas de nutrition et de santé normaux, évoluer régulièrement et sans interruption. L'importance respective de l'augmentation du nombre des cellules et de leur volume dépend du stade d'évolution du dépôt. Pendant la première étape de la formation du dépôt, la croissance du nombre de cellules est de toute évidence le facteur prédominant. Par la suite, les estimations sont difficiles et incertaines; l'âge de l'animal, la nutrition et, en particulier, l'apport quantitatif et qualitatif en lipides sont des facteurs pour lesquels des modifications ont été constatées. Les nouveaux préadipocytes semblent provenir en majorité des capillaires néoformés tandis qu'un pourcentage relativement faible d'entre eux ont pour origine les capillaires préformés.

L'architecture du dépôt précédemment observé se transforme à partir du moment où l'accroissement du dépôt se fait en épaisseur, c'est-à-dire lorsque de nouveaux agrégats de cellules adipeuses commencent à se déposer des deux côtés de la couche occupant le plan du mésentère. Les capillaires sanguins, qui dans un premier temps, sont disposés surtout en arcades, deviennent progressivement branchés par dichotomie. Les feuillets mésentériques s'écartent l'un de l'autre au fur et à mesure que le dépôt augmente de volume.

\section{C. - Aspect ultrastructural des préadipocytes \\ et des adipocytes mésentériques après la naissance}

\section{r. Préadipocytes.}

\section{a) Évolution des préadipocytes.}

L'évolution des préadipocytes mésentériques du porcelet après la naissance, bien que plus rapide, nous paraît se faire suivant un mécanisme semblable à celui déjà observé chez le fotus du Porc (Vodovar, Desnoyers, Françors, I97I), c'est pourquoi nous ne ferons état de ces transformations que pour les confirmer ou indiquer certaines différences observées pouvant être attribuées à la différence d'âge et au mode de nutrition.

Entre la naissance et l'apparition des agrégats de cellules adipeuses, les préadipocytes, suivant le stade d'évolution, ont leur emplacement autour des capillaires sanguins en formation ou néoformés et une morphologie très proche de celle des préadipocytes avant la naissance. Toutefois, au stade de l'apparition des inclusions lipidiques, le réseau du réticulum endoplasmique rugueux (RER) est plus dense, son orientation selon le grand axe de la cellule est plus régulière et le nombre de ses ribosomes est plus élevé. Les mitochondries, de taille et de forme toujours variables, sont plus nombreuses après la naissance (fig. $I, 6$ ).

Dès l'apparition des agrégats et par la suite, pendant la constitution et la croissance du dépôt adipeux, l'aspect et la distribution topographique des préadipocytes changent. Les préadipocytes sont enserrés entre la paroi des capillaires sanguins et les adipocytes, de sorte que les cellules les moins évoluées sont toujours 
les plus proches de la paroi vasculaire (fig. $3,4,5,12$ ). Cette organisation qui a une influence sur la forme des cellules confirme également que la provenance des préadipocytes mésentériques après la naissance est périvasculaire comme avant la naissance.

Dans toutes les observations des coupes mésentériques jusqu'à l'âge de douze à quinze jours, le glycogène, en quantité variable mais généralement abondant, précède et accompagne l'apparition et la croissance des inclusions lipidiques à tous les stades de l'évolution de la cellule adipeuse (fig. 7). A partir de cet âge et de façon irrégulière, la quantité de glycogène par préadipocyte diminue et il est complètement absent, dans la plupart des cas, à l'âge de trois ou quatre semaines. La diminution ou l'absence de glycogène dans les cellules adipeuses correspond très probablement à la diminution de la lipogenèse intracellulaire et à l'augmentation de l'apport en acide gras de l'extérieur de la cellule. Il faut cependant souligner que ces processus sont fonction de la nutrition. Ainsi, comme l'indiquent nos observations actuelles, si on remplace le nutriment habituel par des aliments lipidoprives et riches en glucides, l'apparition du glycogène dans les cellules adipeuses est immédiate et très abondante quel que soit l'âge de l'animal.

L'apparition des premières inclusions lipidiques dans les préadipocytes est observée à ce stade comme avant la naissance dans n'importe quelle partie du cytoplasme (fig. 3, 5, 6, 7)., et apparemment sans ordre prédéterminé tant que les cellules contiennent du glycogène. Avec la diminution, puis la disparition du glycogène, les premières inclusions sont observées plus fréquemment dans le cytoplasme périphérique des cellules.

Le mécanisme de l'accumulation des lipides s'effectue de façon comparable à ce qui a été observé avant la naissance par accroissement des inclusions, par leur fusionnement et par apparition de nouvelles inclusions. La répartition de la matrice fondamentale du cytoplasme et des organites cellulaires varie d'une cellule à l'autre au cours de l'évolution d'un préadipocyte. Cette diversité d'aspect semble dépendre en grande partie du mode de distribution des premières inclusions lipidiques. Ainsi, quand les premières inclusions lipidiques apparaîssent groupées, leur fusion est généralement très rapide : il se forme une masse lipidique centrale et la totalité du cytoplasme avec les organites est repoussée rapidement vers la périphérie (fig. 2, 3). En revanche, quand les premières inclusions sont disséminées et éloignées les unes des autres, le contenu cellulaire est en partie repoussé vers la périphérie, le reste est fragmenté entre les inclusions lipidiques et dégradé par la suite (fig. 4, 5). Dans le premier cas, les préadipocytes parviennent plus rapidement au stade d'adipocytes que dans le second cas et cela quelle que soit la quantité de lipides accumulés. Ces deux modes d'évolution des préadipocytes sont généralement observés en même temps, cependant, le premier semble plus fréquent jusqu'à la formation des agrégats de cellules adipeuses; le second devient prédominant au fur et à mesure que le dépôt adipeux se développe.

b) Les organites cellulaires des préadipocytes au cours de l'accumulation des lipides.

L'appareil de Golgi (fig. 5, 6), formé comme avant la naissance d'un nombre réduit de saccules et de vésicules, est situé assez régulièrement près du noyau chez les préadipocytes avant 1'apparition des inclusions lipidiques; il est, sauf de rares 
exceptions, le premier organite à être dégradé presque immédiatement après l'apparition des lipides dans la cellule.

Le RER, situé pour sa plus grande part, dans les extensions cytoplasmiques et orienté suivant le grand axe des préadipocytes (fig. I, 2, 4), est dégradé aussitôt que l'accumulation des lipides devient importante. Dans un premier temps, il est coupé en fragments plus ou moins courts, souvent élargis et remplis de substance relativement opaque (fig. 8), qui disparaissent en partie ou en totalité avant que les préadipocytes ne parviennent au stade d'adipocytes.

L'aspect et le moment de la dégradation et de la disparition de l'appareil de Golgi et du RER, variables d'une cellule à l'autre, sont accompagnés dans la majorité des cas par l'apparition du réticulum endoplasmique lisse (REL) dans le cytoplasme observé sous forme de vésicules ou de fragments tubulaires plus ou moins longs (fig. 8).

Les mitochondries sphériques, en bâtonnets ou ramifiées sont les plus nombreuses au moment de l'apparition des premières inclusions lipidiques, leurs crêtes sont irrégulières et d'orientations très diverses, leur matrice est généralement peu contrastée (fig. 7). Au fur et à mesure de l'accumulation des lipides dans la cellule, les mitochondries sont généralement repoussées vers la périphérie et un certain nombre d'entre elles sont dégradées avant le passage du stade de préadipocyte à celui d'adipocyte (fig. 9). Cette dégradation se traduit, soit par la dégénérescence des mitochondries en corps denses, vacuolés ou non, soit par l'apparition de nombreux grains opaques dans leur matrice et la disparition des crêtes. Dans les deux cas, les mitochondries disparaissent assez rapidement.

Le noyau, primitivement ovale, puis sphérique avec un, deux ou rarement trois nucléoles, est, sauf de rares exceptions, repoussé à la périphérie contre la membrane plasmique (fig. I, 3, 4, 5). A ce stade, sa forme est souvent différente d'une cellule à l'autre; le nucléoplasme grumeleux au début devient homogène.

Au cours de l'évolution des préadipocytes, le cytoplasme contenant les organites non dégradés et irrégulièrement répartis, est repoussé à la périphérie des cellules et comprimé contre la membrane plasmique sous la forme d'un anneau (fig. 2, 3, Io). Le contraste de la matrice fondamentale du cytoplasme diffère souvent d'une cellule à l'autre et parfois selon les régions d'une même cellule.

A tous les moments de l'évolution des préadipocytes, on observe que la membrane plasmique peut avoir un aspect différent d'une cellule à l'autre, et dans certains cas, sur le pourtour d'une même cellule. Cette membrane est souvent pourvue de micro-invaginations pinocytotiques (fig. II), dont le nombre varie considérablement, et il n'est pas rare de voir que le pourtour des préadipocytes est limité par des microvésicules provenant probablement en grande partie sinon en totalité de la membrane plasmique (fig. 9). Assez couramment, des fibres conjonctives sont entremêlées avec la couche périphérique, et la membrane plasmique présente un aspect effiloché et entrecoupé (fig. 8, 9). Dans d'autres cas, sur le pourtour des préadipocytes, la structure est dégradée, mal définie ou absente ce qui semble indiquer un début de dégénérescence de ces cellules.

La lame basale, qui entoure les préadipocytes et par suite les adipocytes, est comme la membrane plasmique, d'aspect très variable et il semble qu'une interdépendance entre ces deux éléments cellulaires soit constante. En effet, lorsque la structure de la membrane plasmique est bien préservée (fig. II), la lame basale 
est régulière en densité et en épaisseur. Si cela n'est pas le cas, la lame basale est effilochée, entrecoupée et parfois non apparente en partie ou en totalité (fig. 8).

Ces différents aspects de la membrane plasmique et de la lame basale des préadipocytes et des adipocytes et la relation des cellules adipeuses entre elles, d'une part, et avec les capillaires sanguins, d'autre part, feront l'objet d'une autre étude.

\section{c) Taille et forme des préadipocytes.}

Si l'évolution structurale et ultrastructurale est effective dès l'apparition des préadipocytes, l'augmentation de leur taille est surtout importante au cours de l'accumulation des lipides. Le volume des préadipocytes au moment de l'apparition des premières inclusions lipidiques est difficile à apprécier en raison des extensions cytoplasmiques irrégulièrement présentes selon l'incidence des coupes (fig. 5). Pour cette raison, et du fait que les préadipocytes, présumés correspondre au même stade d'évolution, ne sont pas toujours de même volume, nos déterminations de l'accroissement de leurs tailles au cours de l'accumulation des lipides demeurent approximatives. Les nombreuses mesures que nous avons effectuées notamment par les méthodes stéréologiques permettent d'estimer que, entre 1'apparition des premières inclusions lipidiques dans les préadipocytes et leur passage au stade d'adipocytes, il y a une augmentation moyenne du volume d'environ 8 fois. D'autre part, on peut noter que les préadipocytes parvenus au stade d'adipocytes ont, en moyenne, une taille plus élevée après la naissance que pendant la vie prénatale. Ces constatations correspondent très probablement à un changement du rapport entre la prolifération des préadipocytes et la quantité de lipide disponible pour l'accumulation.

Parallèlement à l'augmentation de volume, les préadipocytes changent de forme. Ce changement, tant que les cellules restent isolées, dépend de la forme des préadipocytes avant les inclusions, du lieu de l'apparition des premières inclusions et de leur évolution dont nous avons déjà parlé. Dans la majorité des cas, les préadipocytes au terme de leur évolution quand ils sont isolés, ont une forme sphérique ou ovale. A partir du moment où ils appartiennent aux agrégats de cellules, leur forme est, en premier lieu, fonction des emplacements disponibles, si les préadipocytes croîssent sans être trop comprimés, les formes sphérique ou ovale restent prédominantes (fig. I, 5) ; dans les autres cas, plus fréquents, on observe les formes les plus variées et les cellules adipeuses se modèlent autour des capillaires sanguins et entre les cellules adjacentes.

\section{Préadipocytes parvenus au stade d'adipocytes.}

Le passage du stade de préadipocytes au stade d'adipocytes est caractérisé par la présence d'une masse lipidique relativement homogène entourée du reste cytoplasmique contenant les organiques cellulaires non dégradés. Le cytoplasme est limité à l'extérieur par la membrane plasmique, elle-même entourée par une lame basale (fig. 2, 3, I0, I2). Les éléments indiqués diffèrent souvent, aussi bien par leur aspect que par leur importance; certains sont parfois non apparents en partie ou en totalité. L'importance quantitative de la masse lipidique, d'une part, et de l'anneau périphérique contenant les éléments cellulaires d'autre part, varie considérablement au moment de l'apparition des adipocytes; elle est en grande partie dépendante du mode d'évolution déjà relaté, des préadipocytes. 
Pour un adipocyte, dont le diamètre à ce stade, pourrait être grossièrement évalué égal ou supérieur à $40 \mu$, le diamètre de l'anneau périphérique dans un nombre important de cas, sera compris, suivant la cellule et suivant le pourtour d'une même cellule, excepté au niveau de l'emplacement du noyau, entre $200 \AA$ et $5000 \AA$. Bien que les grandeurs indiquées représentent les moyennes de très nombreux cas observés et mesurés, leurs valeurs ne peuvent avoir qu'une signification tout à fait relative. Dans les conditions de nos observations, la masse lipidique des adipocytes au moment de leur apparition sera plus importante chez un animal âgé que chez un jeune animal.

Ia matrice fondamentale du cytoplasme, compressée dans l'anneau périphérique des adipocytes, présente des zones différemment contrastées comme au stade des préadipocytes. A ce premier stade des adipocytes, l'appareil de Golgi, déjà dégradé dans la plupart des cas, n'est observé que très exceptionnellement dans l'anneau périphérique. Des fragments de RER sont présents dans la majorité des cas, ainsi que des éléments du REI, en particulier sous forme de vésicules.

Les mitochondries, dont le nombre est difficile à évaluer en raison de leur dissémination irrégulière dans l'anneau périphérique sont de forme et d'aspect variés. Chez des animaux placés dans les mêmes conditions nutritionnelles et parfois chez un même animal et sur la même coupe, on observe des mitochondries à matrice très contrastée et sans distinction de crêtes, et des mitochondries à matrice peu contrastée et dont les crêtes d'orientation irrégulière sont apparentes, au moins en partie. Cette diversité des mitochondries est principalement due à leur état fonctionnel différent à un même moment.

Le noyau déjà situé à la périphérie est parfois entouré d'une couche plus ou moins mince de cytoplasme ou bien il est inséré entre la membrane plasmique et les lipides, qui sont en contact avec la membrane nucléaire. Le noyau présente des aspects divers tant en ce qui concerne sa forme (aplati, triangulaire, en forme de croissant ou autre) que la densité de son nucléoplasme.

\section{3. Évolution des adipocytes.}

Parvenues au stade d'adipocytes, ces cellules n'en ont pas pour autant terminé leur évolution; celle-ci est étroitement liée à la résultante de leurs échanges, c'est-à-dire à la différence entre les lipides accumulés et les lipides libérés. Dans des conditions normales et équilibrées de nutrition et, en particulier, chez les animaux jeunes, l'évolution se poursuit par l'accumulation des lipides; cette accumulation entraîne une augmentation du volume et s'accompagne d'une dégradation des éléments cellulaires contenus dans l'anneau périphérique. Cette dégradation a pu être observée pour tous les éléments excepté pour le noyau, dont le devenir n'a pu être mis en évidence de façon satisfaisante jusqu'à présent. Comme cela a été dit pour les préadipocytes, l'augmentation du volume cellulaire au cours de l'évolution des adipocytes est difficile à déterminer d'une façon rigoureuse quel que soit le mode d'évaluation. Néanmoins, on peut estimer que les adipocytes mésentériques au stade présumé " terminal " de leur évolution ont un diamètre le plus souvent compris entre 90 et IIo $\mu$.

Le stade " terminal " de l'évolution des adipocytes doit être considéré comme la limite à partir de laquelle la cellule adipeuse ne pourrait régénérer si les lipides qu'elle contient étaient mobilisés par un régime approprié. Au point de vue biolo- 
gique, nous avons considéré comme adipocytes au stade terminal de l'évolution toutes les cellules adipeuses dont 1'anneau périphérique est très appauvri en cytoplasme et dans lesquelles les organites cellulaires, et notamment les mitochondries, sont devenus très rares ou absents du fait de leur dégénérescence et de leur dégradation (fig. Io, I2).

A partir de ce moment, en raison de cette transformation ultrastructurale, les échanges avec le milieu environnant qui, jusqu'alors, paraissaient être très actifs, semblent diminuer progressivement. L'anneau périphérique des adipocytes se réduit à une bordure plus ou moins opaque dont la structure est difficile à distinguer (fig. I3, I4). Après les observations faites au cours de la croissance et de la mobilisation des dépôts (observations non publiées), nous pensons que ce stade correspond à la spécialisation maximale de la cellule pour la fonction d'accumulation et qu'à partir de ce moment son renouvellement se fera très rapidement.

\section{DISCUSSION}

En nous appuyant sur les éléments cellulaires les plus nombreux et les plus reproductibles, nous avons montré le mécanisme de la formation et de la croissance du dépôt adipeux mésentérique du Porc, dont l'apparition est située entre le septième et le dixième jour après la naissance. L'origine périvasculaire des cellules adipeuses, observée chez le fœtus (VoDOVAR, DESNOYERs, Françors, I97I), a été confirmée et l'évolution des préadipocytes et des adipocytes, entre la naissance et l'apparition du dépôt adipeux puis pendant son développement, a été mise en évidence. Toutefois, il est nécessaire de préciser que les cellules adipeuses mésentériques du Porc, en raison de leur degré différent d'évolution et de leur état fonctionnel qui varie a un même moment, ont un aspect structural et ultrastructural très polymorphe ce qui rend l'interprétation de nos observations parfois complexe et incertaine.

\section{I. - Édification du dépôt adipeux mésentérique}

Nous avons pu constater, au cours de nos observations, que la prolifération des préadipocytes et l'accumulation des lipides à un niveau donné du dépôt mésentérique et pour un intervalle de temps déterminé sont plus rapides immédiatement après la naissance que pendant la période fotale étudiée antérieurement (VodovaR, DESNOYERS, FRANÇOIS, I97I).

La formation des agrégats et l'édification du dépôt adipeux mésentérique se font essentiellement par l'accroissement du nombre et du volume des cellules adipeuses, tandis que le rapprochement de ces cellules ne semble pas intervenir au cours de ces processus.

La prolifération des préadipocytes et l'accumulation des lipides, comme nous l'avons indiqué précédemment, sont nettement influencées par l'âge et la nourriture de l'animal. 'Toutefois, il est bien connu que d'autres facteurs et notamment les différentes hormones (RoDBELL, I964a; CARLSON, MICHELI, I970) interviennent dans ces processus. Il est évident que sans la connaissance de leur mode d'action les 
problèmes se rapportant à l'emplacement des dépôts adipeux, à la prolifération des préadipocytes, à l'accumulation et à la mobilisation des lipides, ne pourront être résolus.

\section{2. - Préadipocytes et adipocytes mésentériques du porcelet après la naissance}

\section{a) Origine des préadipocytes.}

Nos observations montrent que les préadipocytes mésentériques des porcelets après la naissance sont d'origine périvasculaire, ce qui est en accord avec les travaux de Simon (Srmon, I962, I965) concernant plusieurs dépôts adipeux de 1'Homme. Elles confirment et complètent l'étude faite sur le fœtus du Porc (Vodovar, DEsNOYERS, Françors, I97I) par laquelle ont été mis en évidence le mécanisme de la séparation des péricytes de la paroi capillaire puis leur évolution jusqu'au stade d'adipocytes. Ce dernier travail a montré que les éléments cellulaires entre les feuillets mésentériques sont rares au moment de l'apparition des premiers préadipocytes et en particulier on observe ni fibroblastes, ni organes primitifs qui seraient, d'après certains auteurs, l'origine des adipocytes (NAPOLITANO, I963; WASSERMANN, MCDONAID, I963; WASSERMANN, I965). D'autre part, la pauvreté en lipides, pendant la vie embryonnaire de 1'espèce étudiée, I,5 p. Ioo du poids total (GoRTNER, I945), se traduit par une apparition relativement lente des inclusions lipidiques, ce qui a permis des observations relativement rigoureuses sur l'évolution des préadipocytes et des adipocytes.

Dès l'apparition des agrégats de cellules adipeuses, les préadipocytes les moins évolués, c'est-à-dire les plus jeunes, sont constamment observés entre la paroi capillaire et les cellules adipeuses plus évoluées. Cet emplacement topographique des jeunes préadipocytes s'ajoute à l'ensemble des autres indices d'observation pour témoigner de leur provenance périvasculaire. En effet, sachant que les cellules adipeuses ne se divisent pas, il est difficile de concevoir que des préadipocytes provenant d'une autre source viennent se placer régulièrement contre les parois capillaires. Pour réfuter l'origine périvasculaire des adipocytes, FUJITA et ASAGAMI (I970) dans leurs travaux sur le fœtus humain, invoquent l'absence de lame basale autour des cellules endothéliales; de plus, ils indiquent n'avoir jamais observé de lipides, de glycogène et de microvésicules dans ces cellules. Au cours de nos études sur le mésentère du fotus de Porc et du porcelet après la naissance, nous avons cependant toujours observé une lame basale autour des péricytes capillaires et très fréquemment des lipides, du glycogène et des microvésicules dans ces cellules.

Comme raisons possibles des divergences des chercheurs sur l'origine des adipocytes, on peut invoquer le fait que les observations en microscopie électronique, les seules susceptibles de résoudre le problème, n'ont tenu compte jusqu'à présent ni de l'espèce, ni de la nature des dépôts, ni de l'âge de l'animal.

Or, comme Napolitano (NAPolitano, I963) le suggère, il est possible que l'origine des préadipocytes ne soit pas la même pour tous les dépôts et à tous les moments; de même, il n'est pas exclu que dans certaines conditions et dans un même dépôt, des cellules d'origine variable puissent acquérir la capacité d'accumuler des lipides. Si on considère les dépôts adipeux pathologiques, en prenant comme exemple l'accumulation des lipides dans le foie, on constate que les hépatocytes sont 
devenus des adipocytes au degré le plus élevé de l'accumulation des lipides. D'autre part, il a été observé chez le fotus du Porc (Vodovar, Desnoyers, François, r97I) que, avant l'apparition des cellules adipeuses, des lipides étaient souvent accumulés dans les cellules qui forment la paroi capillaire. En conclusion, de nouvelles investigations seront nécessaires avant de proposer des solutions à l'ensemble des questions posées.

\section{b) Prolifération des préadipocytes.}

Jusqu'à l'âge de dix jours, ce qui correspond à l'apparition du dépôt adipeux, l'observation de la prolifération des préadipocytes n'est pas trop entravée par les éléments cellulaires qui sont encore relativement peu nombreux à ce stade entre les feuillets mésentériques. A partir de ce moment jusqu'à l'âge de quarante-cinq jours, c'est-à-dire pendant toute la période de nos observations, la prolifération des préadipocytes reste également importante ce qui confirme les travaux faits sur d'autres espèces à un âge correspondant (ENESCO, LEBLOND, I962 ; ZINGG, ANGEL, SteINBERG, I962 ; HIRSH, HAN, I969). Cependant, au cours de cette seconde étape d'observations, nous ne sommes parvenus à nous faire une opinion précise ni sur le rythme de l'apparition des préadipocytes ni sur leur nombre et nous ne pouvons pas dire si l'intensité de la prolifération diffère selon les périodes comme certains auteurs le présument (ENESCO, LEBL,OND, I962). Pour essayer de résoudre ce problème, des investigations concernant 1'apparition quantitative de nouvelles cellules dans les dépôts adipeux sont nécessaires.

Au stade de l'apparition des agrégats de cellules adipeuses et pendant l'édification du dépôt, le réseau de microcirculation terminal mésentérique semble se développer régulièrement et rapidement. Par la suite, au fur et à mesure de la croissance du dépôt adipeux, la vascularisation à sa périphérie et surtout vers la région pariétale du mésentère se poursuit activement tandis qu'à l'intérieur du dépôt il semble que la formation des capillaires et l'apparition de jeunes préadipocytes diminuent. Il est toutefois possible que ce ralentissement de la prolifération des capillaires et des préadipocytes à l'intérieur du dépôt adipeux soit, en partie, apparent à cause de l'augmentation de la taille des adipocytes qui a pour conséquence la diminution de la densité des capillaires par unité de volume; toutefois, les observations en cours sur le dépôt adipeux du Porc adulte montrent nettement que le nombre de jeunes préadipocytes est de toute évidence très réduit par rapport à ce que l'on observe jusqu'à l'âge de quarante-cinq jours. Ces observations sont en accord avec les travaux sur le renouvellement des cellules adipeuses (LEBlond, Messier, Kopriva, I959; Helliman, Hellerström, I96I) sur d'autres espèces ; elles sont aussi susceptibles d'expliquer, au moins en partie, la répercussion de la nutrition des jeunes animaux sur l'importance ultérieure du dépôt adipeux (KNITTLE, HIRSH, I968).

\section{c) Volume des cellules adipeuses mésentériques.}

L'évolution des préadipocytes jusqu'à l'apparition des premières inclusions lipidiques dans leur cytoplasme se caractérise par un changement de forme et une transformation ultrastructurale sans que des augmentations importantes se produisent dans leur volume. En conséquence, l'augmentation de volume des cellules 
adipeuses, dont nous avons indiqué très grossièrement les limites, doit être attribuée en totalité à l'accumulation des lipides. Par contre, le volume des lipides accumulés est souvent supérieur à l'accroissement du volume cellulaire, la matrice fondamentale cytoplasmique étant comprimée par la masse lipidique et une partie des organites cellulaires étant dégradée.

Pour la détermination du nombre et du volume des cellules adipeuses, plusieurs méthodes ont été proposées. La technique biochimique basée sur le dosage du DNA et l'extraction des lipides (Peckham, Entenman, Carrol, ig62 ; RaUlin, Launay, I967) ne semble pas donner satisfaction, le DNA présent dans les éléments autres que les cellules adipeuses étant proportionnellement important (RODBELI, I964 $b$ ). Les procédés physiques par comptage électronique des particules et détermination de leur taille (HIRSh, GalliaN, I968; Hirsh, HaN, I969) ne permettent pas de tenir compte de la réalité structurale et ultrastructurale qui varie d'une cellule à l'autre quelle que soit la taille. Jusqu'à présent, les techniques histologiques en microscopie optique (GolDRICK, I967 ; LAUNAY, Vodovar, RAULIN, I968 ; LEMONNIER, I970) n'ont pas donné les satisfactions escomptées : l'incidence des coupes est rarement celle qui passe par le centre de plusieurs cellules, d'autre part l'environnement, 1'aspect ultrastructural et la forme sont négligés. La microscopie électronique, en particulier par l'application des méthodes stéréologiques (WEIBEL, KISTIER, SCHERLE, I966), semble donner les résultats les plus proches de la vérité, bien qu'à partir d'un moment donné de l'évolution du dépôt adipeux, la très grande taille des cellules diminue les possibilités d'application de cette méthode et que des observations comparatives sur des coupes semi-fines sont nécessaires.

\section{d) Accumulation des lipides et niveau d'activité des échanges des cellules adipeuses.}

Les lipides accumulés dans le dépôt adipeux pendant un intervalle de temps donné sont, de toute évidence et sans distinction de nature ni de source, répartis en un grand nombre de cellules adipeuses ayant des stades différents d'évolution. Bien que l'ensemble préadipocytes et adipocytes soit situé dans un milieu qui paraît uniforme et qui contient des acides gras et du glycogène ou les deux en même temps suivant les cas, il n'est pas possible au stade actuel de notre travail, et malgré les observations en cours avec des acides gras marqués, de faire de présomption ni sur le mode de répartition, ni sur les rapports quantitatifs de ces répartitions. Il semble, cependant, qu'un certain nombre d'adipocytes, parvenus au stade " terminal " de leur évolution, ne participent plus à l'accumulation des acides gras se trouvant dans leur environnement. D'autre part, la diversité d'aspect ultrastructural des cellules adipeuses et, en particulier, de leur membrane plasmique et de leurs mitochondries, qui reflètent l'état fonctionnel de ces cellules, permet de penser que, d'une cellule à l'autre, à un même instant et à un même niveau, on assiste, d'une part, à l'accumulation des lipides, et, d'autre part, à leur libération. De ce fait, on peut présumer que les échanges avec l'extérieur, suivant les cellules, se font à un même moment dans deux sens opposés.

Dans le dépôt normal, l'activité des échanges de chaque cellule adipeuse avec le milieu environnant et le sens de ces échanges, accumulation ou libération, ne se font pas, sans aucun doute, au hasard et doivent être liés à de nombreux facteurs. La surface de la cellule, son degré d'évolution, l'importance des espaces intercellulaires, la densité des capillaires sanguins et l'état du milieu environnant sont des 
éléments parmi d'autres dont la participation est incertaine. En résumé, on peut dire que l'activité des cellules adipeuses est très complexe; en effet, les théories successives et contradictoires considérant ces cellules, soit totalement inactives, soit parmi les plus actives, et, dernièrement, actives seulement en partie, montrent bien l'insuffisance de nos connaissances sur ce sujet.

\section{e) Corrélation entre le nombre et la taille des cellules adipeuses.}

L'accroissement du volume d'un dépôt adipeux chez le jeune animal est dû à l'augmentation du nombre des cellules qui ne sont pas toujours en totalité des préadipocytes, à la croissance de la taille des cellules adipeuses par accumulation des lipides et, enfin, à la prolifération des éléments habituellement associés au dépôt adipeux (fibres conjonctives, système microcirculatoire, etc.).

Dès la constitution du dépôt, le quotient se rapportant à l'accumulation des acides gras, d'une part, et à leur mobilisation, d'autre part, est très élevé c'est-àdire que l'accroissement de la masse lipidique est rapide. Pendant la même période, la prolifération des préadipocytes est importante et bien qu'il ne soit pas possible pour l'instant d'affirmer que la présence des lipides interfère directement ou indirectement sur la prolifération des préadipocytes ou inversement, on est cependant amené à penser qu'il existe des relations entre ces deux processus. De l'ensemble de ces corrélations, il résulte à notre avis un équilibre entre le nombre des cellules adipeuses, leur volume et le renouvellement des adipocytes, les rapports entre les éléments de cet équilibre étant variables suivant le moment et, en particulier, suivant l'âge des animaux.

Après la naissance et au début de la formation du dépôt adipeux, le nombre des préadipocytes est très supérieur à celui des adipocytes ; parmi ces derniers, rares sont ceux qui ont atteint le stade "terminal " de leur évolution. Par la suite cet aspect change du fait que le quotient entre les adipocytes et les préadipocytes ne cesse de croître. On peut donc supposer que la prolifération des préadipocytes diminue au fur et à mesure que le dépôt adipeux augmente d'importance ou bien que l'accumulation des lipides devient plus rapide ou encore - et cela nous paraît le plus probable - que les deux phénomènes se manifestent en même temps et sans que les variations soient obligatoirement de même importance.

Le nombre des adipocytes parvenus au stade " terminal " de leur évolution reste relativement peu élevé, ce qui nous autorise à penser que les cellules parvenues à ce stade se renouvellent rapidement. Le mode de maturation des cellules adipeuses, puis leur remplacement dans le dépôt, pourraient être comparés au renouvellement des cellules absorbantes de l'intestin étudié en microscopie optique chez la Souris (LEBLOND, MESSIER, I958), en microscopie électronique chez l'Homme (BROWN, I962) et chez le Porcelet (Vodovar, FlÉchon, I966). Dans les deux cas, les cellules étant parvenues à un stade déterminé de leur évolution ne se divisent plus mais leurs transformations, en vue de l'accomplissement de fonctions spécialisées, se poursuivent et elles disparaîssent au stade le plus élevé de leur perfectionnement. Actuellement, nous ne savons pas quel est le rythme du renouvellement dans les adipocytes et de quels facteurs il dépend. Néanmoins, il nous semble certain que le système microcirculatoire, peu étudié au niveau du dépôt adipeux, doit jouer un rôle de premier ordre. 


\section{REMERCIEMENTS}

Nous sommes très reconnaissants envers M. le Professeur P. Favard pour ses précieux conseils, ses critiques ainsi que pour la correction de notre manuscrit.

\section{SUMMARY}

\section{MESENTERIC ADIPOSE DEPOSIT IN THE PIGLET. MORPHOLOGICAI STUDY}

The organization and development of mesenteric preadipocytes and adipocytes were studied in piglets at birth and during the first forty-five days of life. Until about one week of age, adipose cells are disseminated between the mesenteric leafflets in the adjacent mesenteric part of the intestine. The appearance of preadipocytes and their localization are closely related with the proliferation and the orientation of the blood capillaries.

Towards the age of seven days, we observed the appearance of adipose cell ageregates ; the main characteristic is the mode of distribution of the preadipocytes and adipocytes around the blood capillaries. The mechanism of increase in the adipose cell aggregates and construction of the mesenteric adipose deposit, which appears about the roth day after birth, have been observed. The structural and ultrastructural transformations of the preadipocytes and adipocytes during the development and increase of the adipose deposit are described.

\section{RÉFÉRENCES BIBL,IOGRAPHIQUES}

Barrnett R. J., r96r. In : Kinsell L. W. Adipose tissue as an organ, 3-78, Thomas Ch. C., Springfield, Illinois.

BARrnett R. J., BALl E. G., I960. Metabolic and ultrastructural changes induced in adipose tissue by insulin. J. biophys. biochem. Cytol., 8, 83-10o.

Brows A. L., I962. Microvilli of the human jejunal epithelial cell. J. Cell Biol., 12, 623-627.

Carlson L. A., Michelt H., rg7o. Some characteristics of lipolysis in dog adipose tissue. Effects of noradrenaline, prostaglandin $\mathrm{E}_{1}$ and nicotinic acid. Acta physiol. scand., 79, I45-I52.

Chase W. H., I959 a. Fine structure of Rat adipose tissue. J. Ultrastruct. Res., 2, 283-287.

Chase W. H., r959 b. Structure of basement membranes of fat cells. A. M. A. Arch. Pathol., 67, 550-555.

ENEsco M., LeBLond C. P., 1962. Increase in cell number as a factor in the growth of the organs and tissues of the young male rat. J. Embryol. exp. Morph., 10, 530-562.

Fleming $W$., I87r. On the formation and regression of fat cells in connective tissue with comment on the structure of the latter. Arch. R. mikr. Anat., 7, 32-47.

Fujita H., Asagami C., I97o. Electron microscopy of the embryonic differentiation of fat cells. Congres Micr. Electr., Vol. III, p. 535.

GoldRICK R. B., 1967. Morphological changes in the adipocytes fat deposition and mobilization. Am. J. Physiol., 212, 777-782.

Gortar W. A., I945. The lipids of the pig during embryonic development. J. biol. Chem., 159, I35-I43.

Hellman B., Hellerström C., I96r. Cell renewal in the white and brown fat tissue of the rat. Acta Path. Microbiol. scand., 51, 347-353.

Hirsch J., Gallian E., I 968 . Methods for the determination of adipose cell size in man and animals. J. Lipid Res., 9, I10-1 19.

Hirsch J., HAN P. W., rg69. Cellularity of rat adipose tissue : effects of growth, starvation and obesity. J. Lipid Res., 10, 77-82.

KNITtLe J. L., Hirsch J., I968. Effect of early nutrition on the development of rat epididymal fat pads : cellularity and metabolism. J. Clin. Invest., 47, $2091-2098$. 
Launay M., Vodovar N., Raulin J., 1968. Développement du tissu adipeux. Nombre et taille des cellules en fonction de la valeur énergétique et de l'insaturation des lipides du régime. Bull. Soc. Chim. biol., 50, $439-449$.

LeBlond C, P., Messier B., r958. Renewal of chief cells and goblet cells in the small intestine as shown by radioautography after injection of ${ }^{3} \mathrm{H}$-thymidine into mice. Anat. Rec., 132, $247-259$.

Leblond C. P., Messier B., Kopriva B., I959. Thymidine- $\mathrm{H}^{3}$ as a tool for the investigation of the renewal of cell populations. Lab. Invest., 8, 296-308.

Lemonnier D., I970. Cellularité et caractères morphologiques du tissu adipeux du rat rendu obèse par un régime hyperlipidique. Arch. Anat. micr. Morph. exp., 59, I-7.

LUFT J., r96r. Improvments in epoxy resin embedding methods. J. biophys. biochem. Cytol., 9, 409-4I4.

Millonig G., I96I. The advantages of a phosphate buffer for $\mathrm{OsO}_{4}$ solutions in fixation. $J$. appl. Phys., 32, I637.

Napolitano L., 1963. The differentiation of white adipose cells : an electron microscope study. J. Cell. Biol., 18, 663-679.

Napolitano L., 1965a. In : Handbook of physiology : adipose tissue 5, Iog-I23. Renold A. E., Cahill G. F. Jr, Am. Phys. Soc., Washington D. C.

Napolitano L., 1965 b. Observations on the fine structure of adipose cells. Ann. N. Y. Acad. Sci, 131, 34-42.

Peckham S. C., Entenman C., Carroll H. W., r962. The influence of a hypercaloric diet on gross body and adipose tissue composition in the rat. $J$. Nutr., 77, 187-297.

Raulin J., LAUnay M., I967. Enrichissement en ADN et ARN du tissu adipeux épididymaire du rat par administration de lipides saturés. Nutr. Dieta, 9, 208-221.

REYNolDS E., I963. The use of lead citrate at high $\mathrm{pH}$ as an electron opaque stain in electron microscopy. J. Cell. Biol., 17, 208-212,

Rodbell M., I964a. Metabolism of isolated fat cells. I. Effects of hormones on glucose metabolism and lipolysis. J. Biol. Chem., 239, 375-38o.

Ropbell M., r964 $b$. Localization of lipoprotein lipase in fat cells of rat adipose tissue. J. Biol. Chem., 239, 753-755.

Sheldon H., rg65. In : Handbook of physiology: adipose tissue, 5, I25-I39. Renold A. E., CAHill G. F. Jr, Am. Phys. Soc., Washington D. C.

Sheldon H., r969. The morphology and growth of adipose tissue. Proc. Meat Ind. Res. Conf., 9-23.

Simon G., I962. Genèse et structure du tissu adipeux chez l'Homme. Acta Anat., 48, $232-241$.

Simon G., rg65. In : Handbook of physiology : adipose tissue, 5, Ior-I07, Renold A. E., CAHILL G. F. Jr., Am. Phys. Soc., Washington D. C.

Told C., I87o. Contribution to the histology and physiology of adipose tissue. Sitzber. Akad. Wiss. Wien. Math. Naturwiss. KI, 62, 445-452.

Vodovar N., Fléchó J., I966. La cellule épithéliale absorbante de l'intestin grêle du Porc : ultrastructure. Ann. Biol, anim. Bioch. Biophys., 6, 13-32.

Vodovar N., Serres F., François A. Ch., ig69. Aspect morphologique de la formation du dépôt adipeux mésentérique chez le porcelet. C. R. Acad. Sci. Paris, 269, 969-97r.

Vodovar N., Desnoyers F., François A. Ch., r97I. Origine et évolution des adipocytes mésentériques du porcelet avant la naissance. Aspect ultrastructural. J. Micr., 11, 265-284.

Wassermani F., I965. In : Hanabook of physiology: adipose tissue, 5, 87-Ioo. Renold A. E., Cahill G. F. Jr., Am. Phys. Soc., Washington D. C.

Wassermann F., Mc Donald T. F., I960 a. Electron microscopic study of the fine structure of the fat cell as related to function. Argone Nat. lab., $A N L, 6264,68-82$.

Wassermann F., Mc Donald T. F., I $960 b$. Electron microscopic investigation of the surface membrane structures of the fat cell and of their changes during depletion of the cell. Z. Zellforsch., 52 , 778-80o.

Wassermann F., Mc Donald T. F., I963. Electron microscopic study of adipose tissue (fat organs) with special reference to the transport of lipids between blood and fat cells. Z. Zellforsch., 59, 326-357.

Weibel E. R., Kistler G. S., Scherle W. F., ig66. Practical stereological methods for morphometric cytology. J. Cell Biol., 30, 23-38.

ZingG W., ANGel A., Steinberg M. D., I962. Studies on the number and volume of fat cells in adipose tissue. Canad. J. Biochem. Physiol., 40, 437-442. 


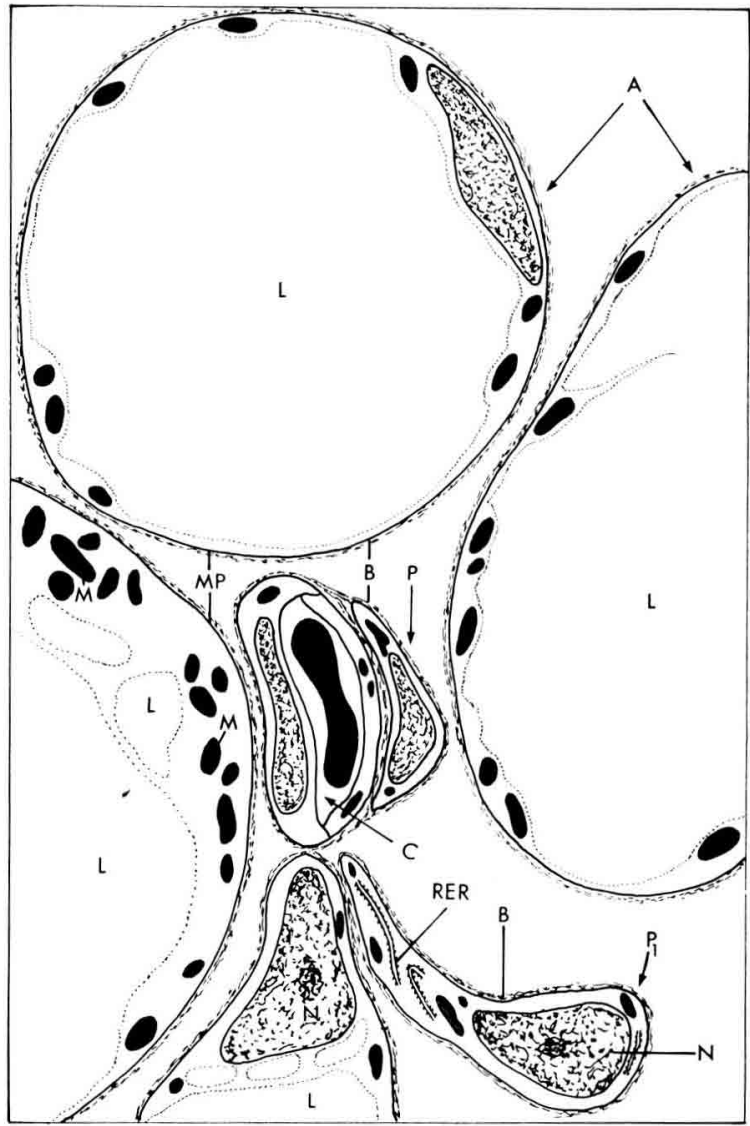

FIG. I. - Schéma d'un agrégat de cellules adipeuses mésentériques chez le porcelet environ une semaine après la naissance

Quatre cellules adipeuses A sont disposées autour d'un capillaire $C$ pourvu d'un péricyte $P$, entouré d'une lame basale en partie commune avec celle du capillaire. Entre les cellules dont les lipides L sont, dans la plupart des cas, fusionnés en une seule masse et le capillaire $\mathrm{C}$, se trouve un préadipocyte $P_{1}$ sans lipides; Noyau, $N$; Mitochondries, $M$; Réticulum endoplasmique rugueux, RER ; membrane plasmique, MP ; Lame basale, $B$.

Échelle approximative $\times 4500$ 


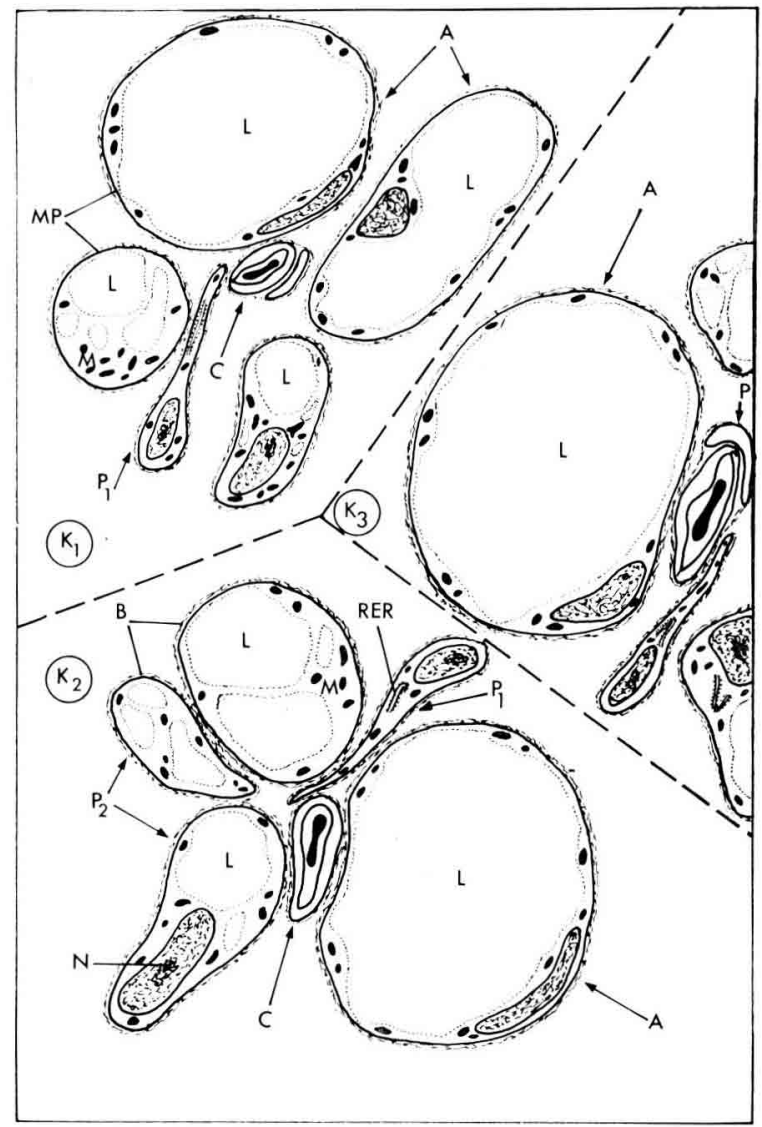

FIG. 2. - Le schéma représente trois agrégats de cellules adipeuses $K_{1}, K_{2}, K_{3}$, plus ou moins parvenus en contact: c'est l'ébauche du dépót adipeux

Les cellules adipeuses $\mathrm{A}$ aux différents degrés d'accumulation des lipides $\mathrm{L}$ sont disposées autour des capillaires sanguins $\mathrm{C}$. Péricytes, $\mathrm{P}$; Préadipocytes sans inclusions lipidiques, $\mathrm{P}_{\mathbf{1}}$; Préadipocytes avec inclusions lipidiques, $\mathbf{P}_{\mathbf{2}}$; Noyau, $\mathbf{N}$; Mitochondries, $\mathrm{M}$; Réticulum endoplasmique rugueux, RER; Membrane plasmique, MP; Lame basale, $B$.

Échelle approximative $\times 2000$ 


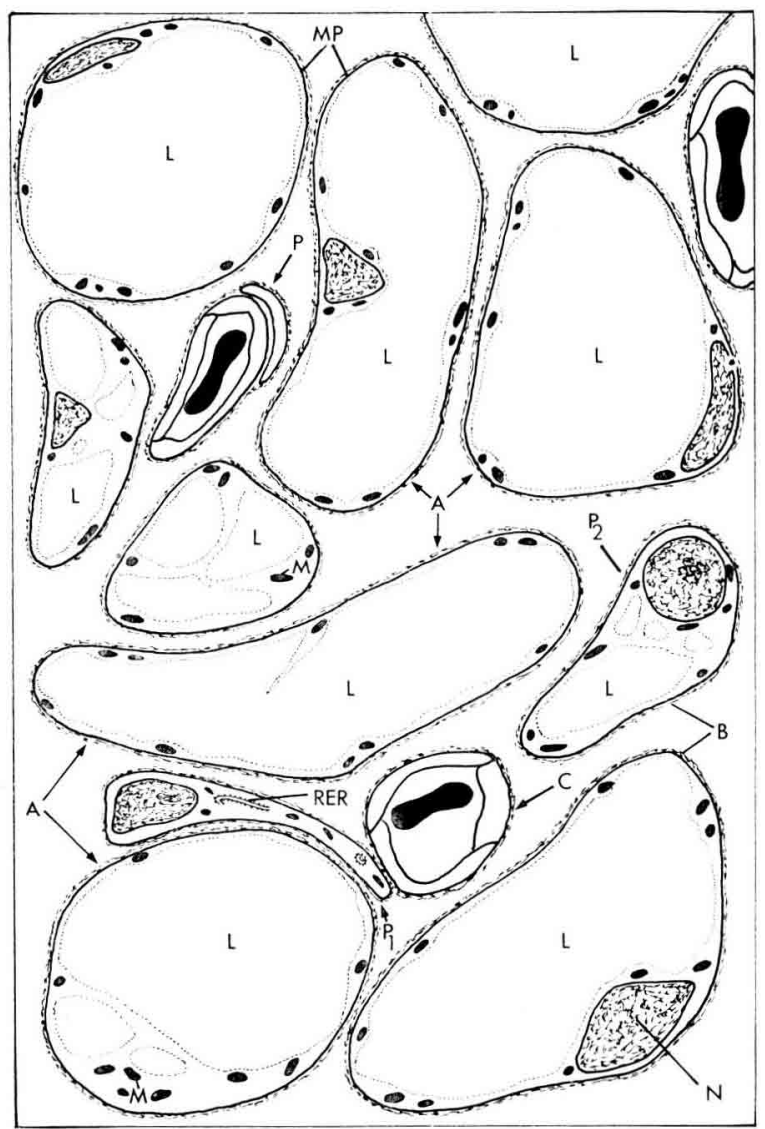

FIG. 3. - Schéma de la répartition des différents éléments du dépót adipeux mésentérique observée aux environs du dixième jour après la naissance du porcelet

Les agrégats de cellules adipeuses A sont parvenus en contact ce qui montre l'aspect du dépôt adipeux. Péricyte, $\mathrm{P}$; Préadipocyte sans inclusions lipidiques, $\mathrm{P}_{1}$; Préadipocytes, $\mathrm{P}_{2}$, avec inclusions lipidiques, L; Capillaires sanguins, $\mathbf{C}$; Noyau, $\mathbf{N}$; Mitochondries, $\mathbf{M}$; Réticulum endoplasmique rugueux, RER ; Membrane plasmique, MP; Lame basale, B.

Échelle approximative $\times 2500$ 


\section{ABREVIATIONS UTILISÉES DANS LES PLANCHES}

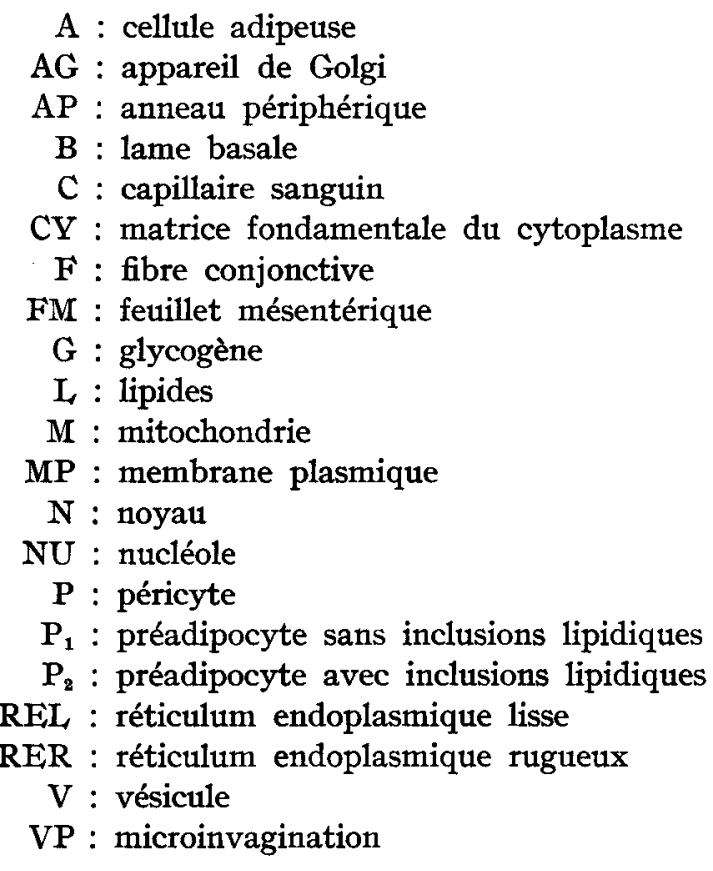

\section{PLANCHE I}

FIG. I.

Coupe de mésentère en bordure de l'intestin montrant l'aspect de la répartition des préadipocytes et des adipocytes à la naissance du porcelet.

Feuillet mésentérique, FM ; Capillaire sanguin, $C$ avec péricyte, $\mathbf{P}$; Préadipocytes sans inclusions lipidiques, $P_{1}$; Préadipocyte avec inclusions lipidiques, $\mathrm{P}_{2} ;$ Adipocytes, $\mathrm{A}$ et leur anneau périphérique, AP ; I,ipides, L, Noyau, $N$; Mitochondries, M; Fibres conjonctives, F. 


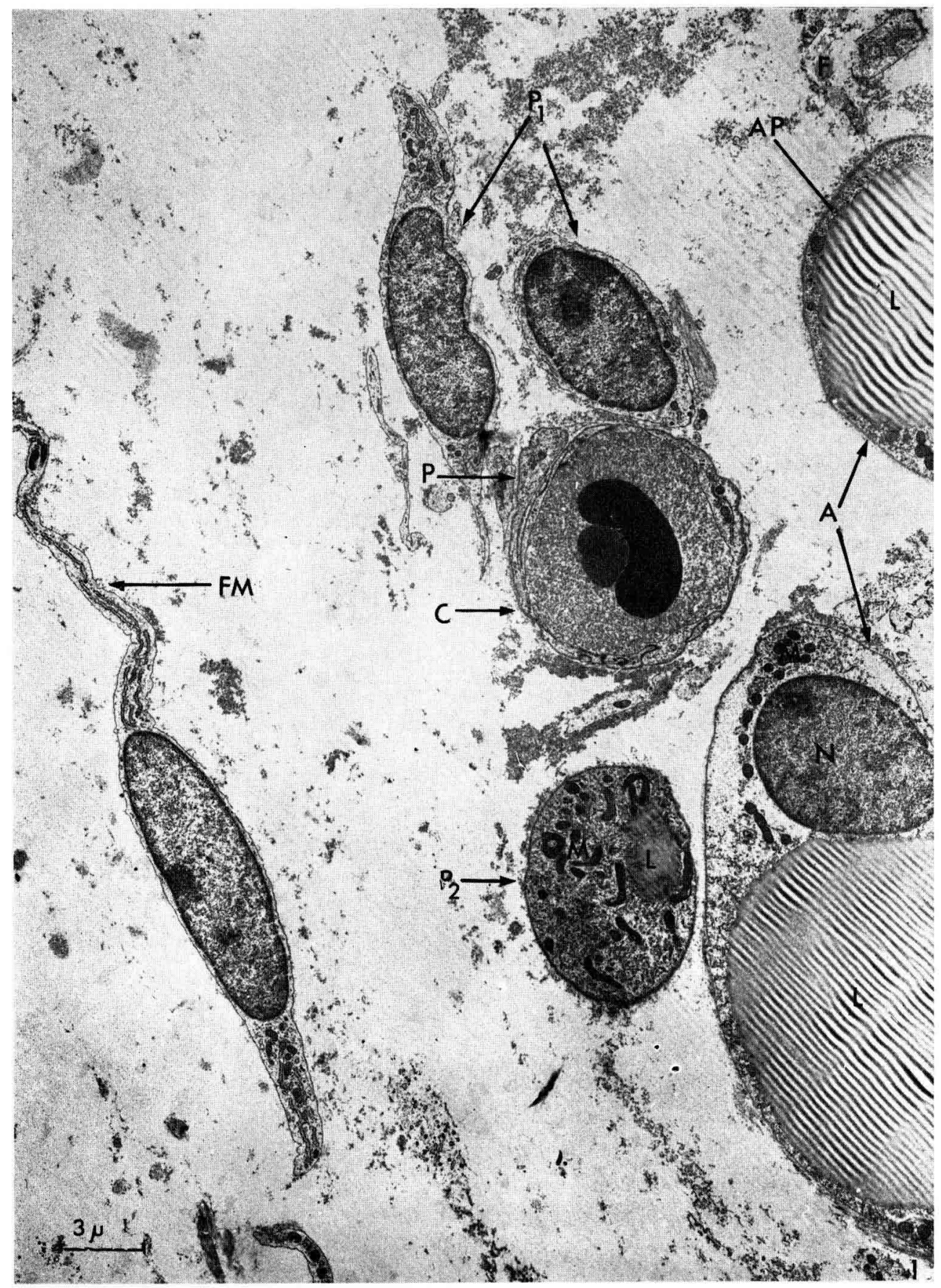




\section{PLANCHE II}

FIG. 2

Quatre préadipocytes $P_{1}$ et un adipocyte $A$ répartis autour d'un capillaire sanguin $C$ non ouvert et entouré d'un péricyte $P$. Lipides, L; Anneau périphérique de l'adipocyte, AP contenant quelques petites inclusions lipidiques; Fibres conjonctives, F $(\times 4.500)$.

FIG. 3

Aspect de la formation d'un agrégat de cellules adipeuses mésentériques sept jours après la naissance du porcelet : adipocytes $\mathrm{A}$ dont l'importance de l'anneau périphérique AP varie d'un adipocyte à l'autre et suivant leur pourtour ; cellule périvasculaire, $\mathrm{P}$, présumée futur adipocyte ; Capillaire sanguin, C ; Noyau, N ; Lipides, $\mathrm{L}(\times 4.500)$. 


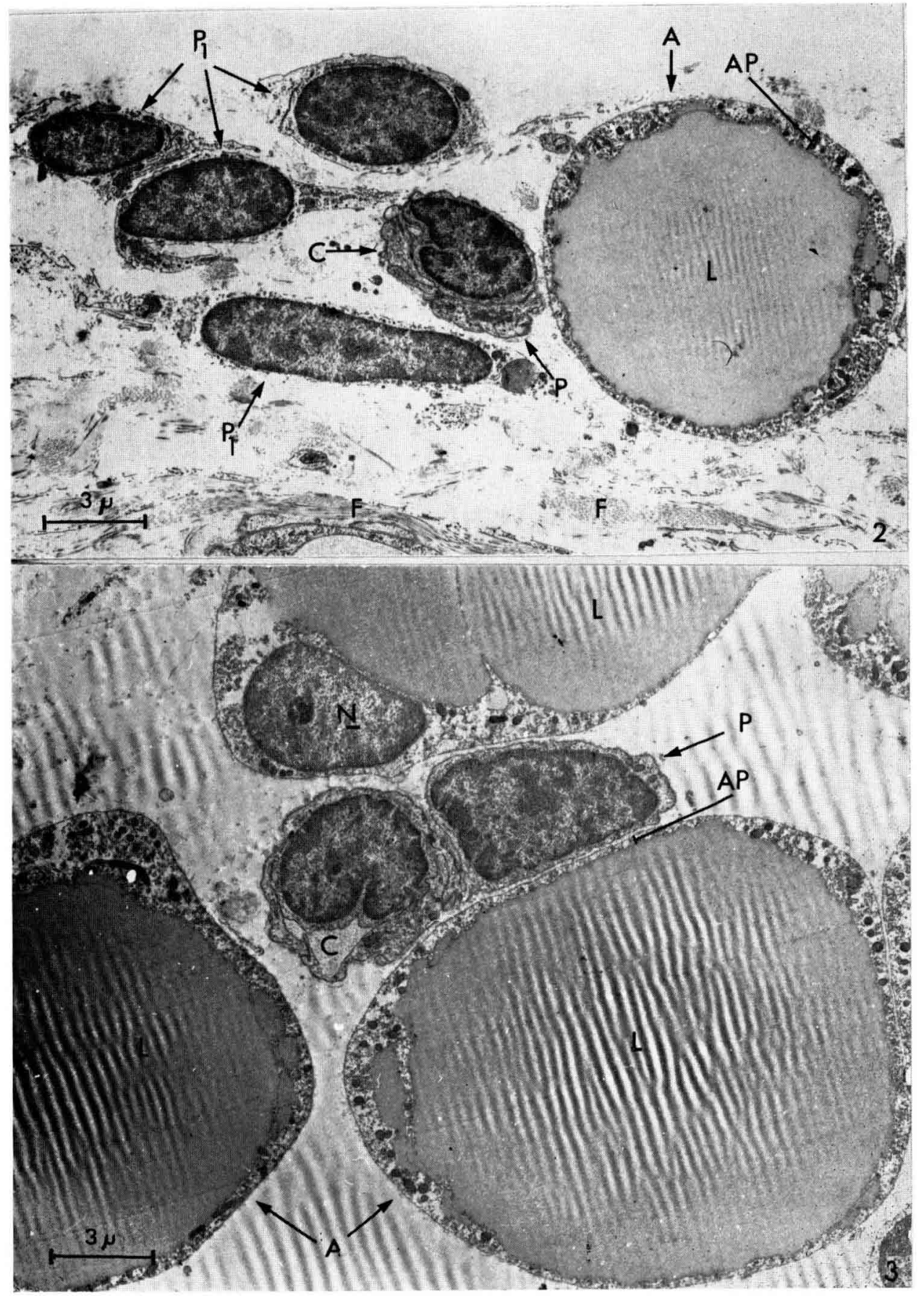


PLANCHE IIJ

FIG. 4

Vue partielle de trois cellules adipeuses $P_{2}$ avec des inclusions lipidiques $L$ d'importance différente; le cytoplasme, $C Y$, est entrecoupé ou repoussé vers la périphérie; le noyau, $N$, et les mitochondries, $M$, sont à la périphérie ; partie d'un préadipocyte $P_{1}$ riche en reticulum endoplasmique rugueux RER et sans inclusions lipidiques; capillaire sanguin $C$ et péricyte $P(\times 6.000)$. 


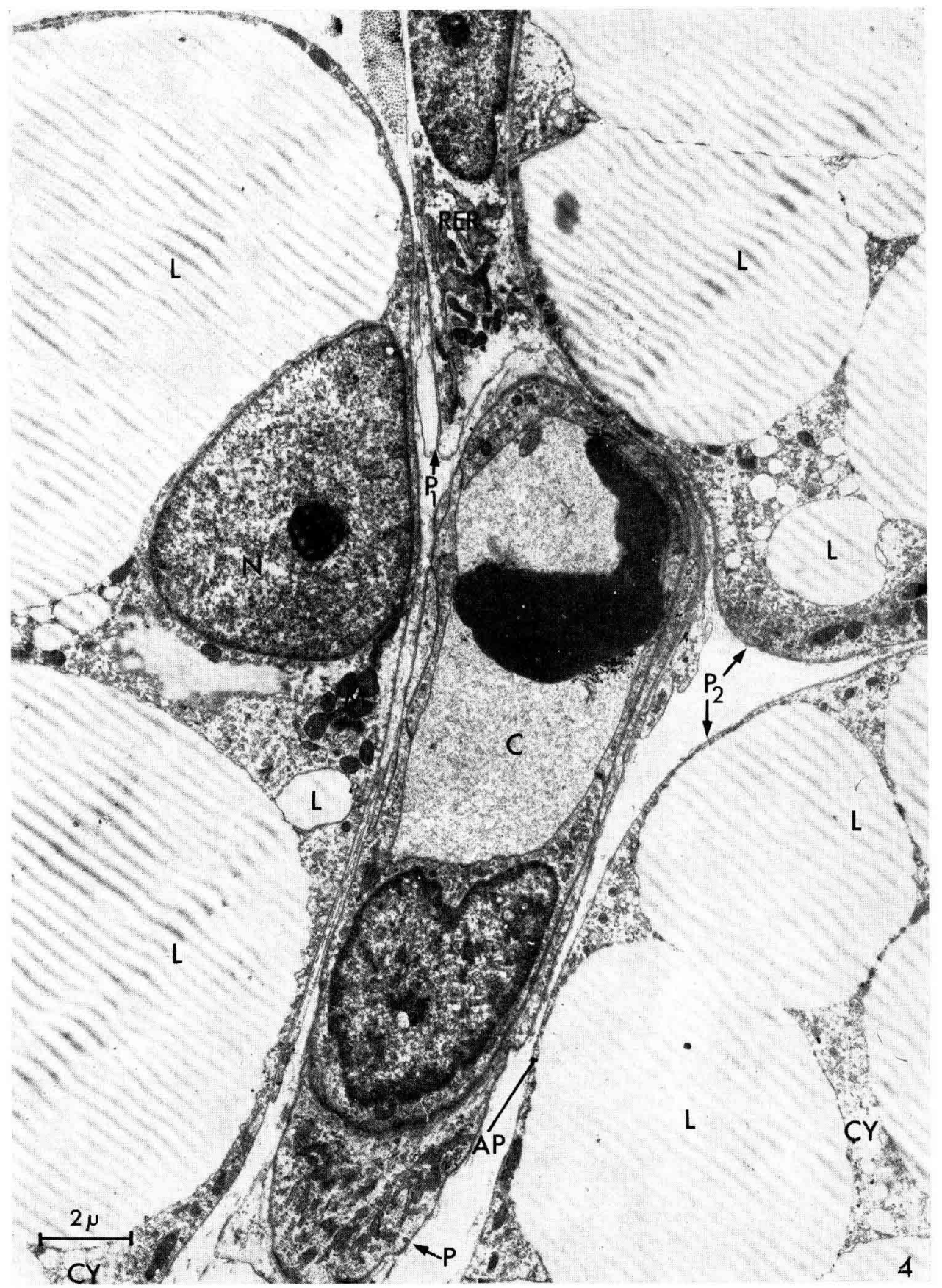




\section{PLANCHE IV}

FIG. 5

Aspect d'une coupe du dépôt mésentérique du porcelet de dix jours. Plusieurs agrégats de cellules adipeuses sont en contact, on n'en distingue plus les limites; cellules adipeuses $P_{2}$ avec des inclusions lipidiques en quantité variable; préadipocyte sạs inclusions lipidiques $P_{1}$; avec appareil de Golgi, AG ; Lipides, L ; Capillaires sanguins, $\mathrm{C}(\times 4.500)$. 


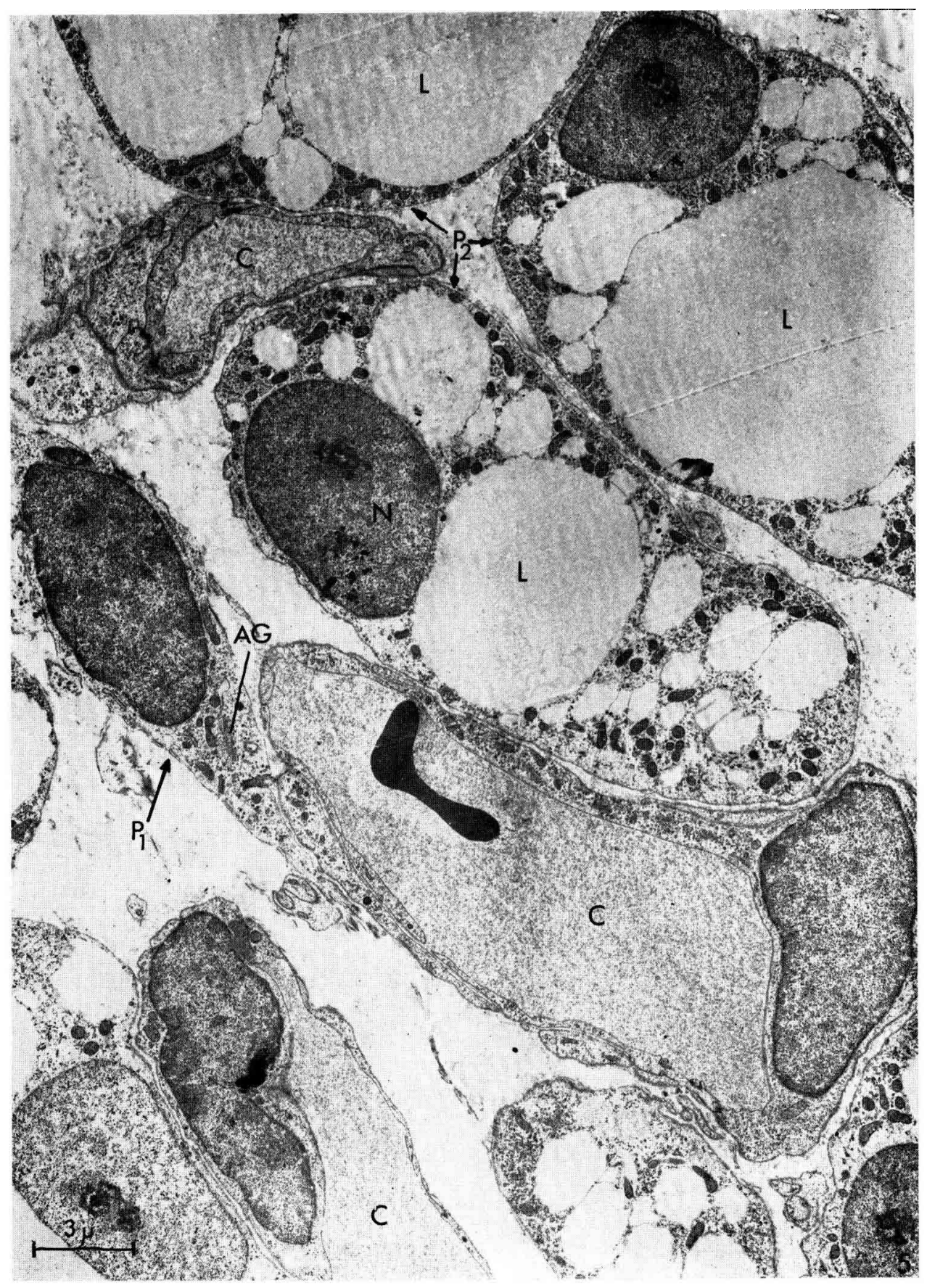




\title{
PLANCHE V
}

\author{
FIG. 6
}

Vue partielle d'un préadipocyte $P_{2}$ avec plusieurs inclusions lipidiques $L$, d'importance différente ; les mitochondries $M$, à ce stade d'évolution, sont en nombre élevé ; noyau, $N$; appareil de Golgi, AG ( $\times$ 9.000).

Fig. 7

Partie de préadipocyte $P_{2}$ avec plusieurs inclusions lipidiques, $L$; importante quantité de glycogène, $G$, irrégulièrement réparti ; mitochondries, M, dont la matrice est peu contrastée $(\times 9.000)$. 


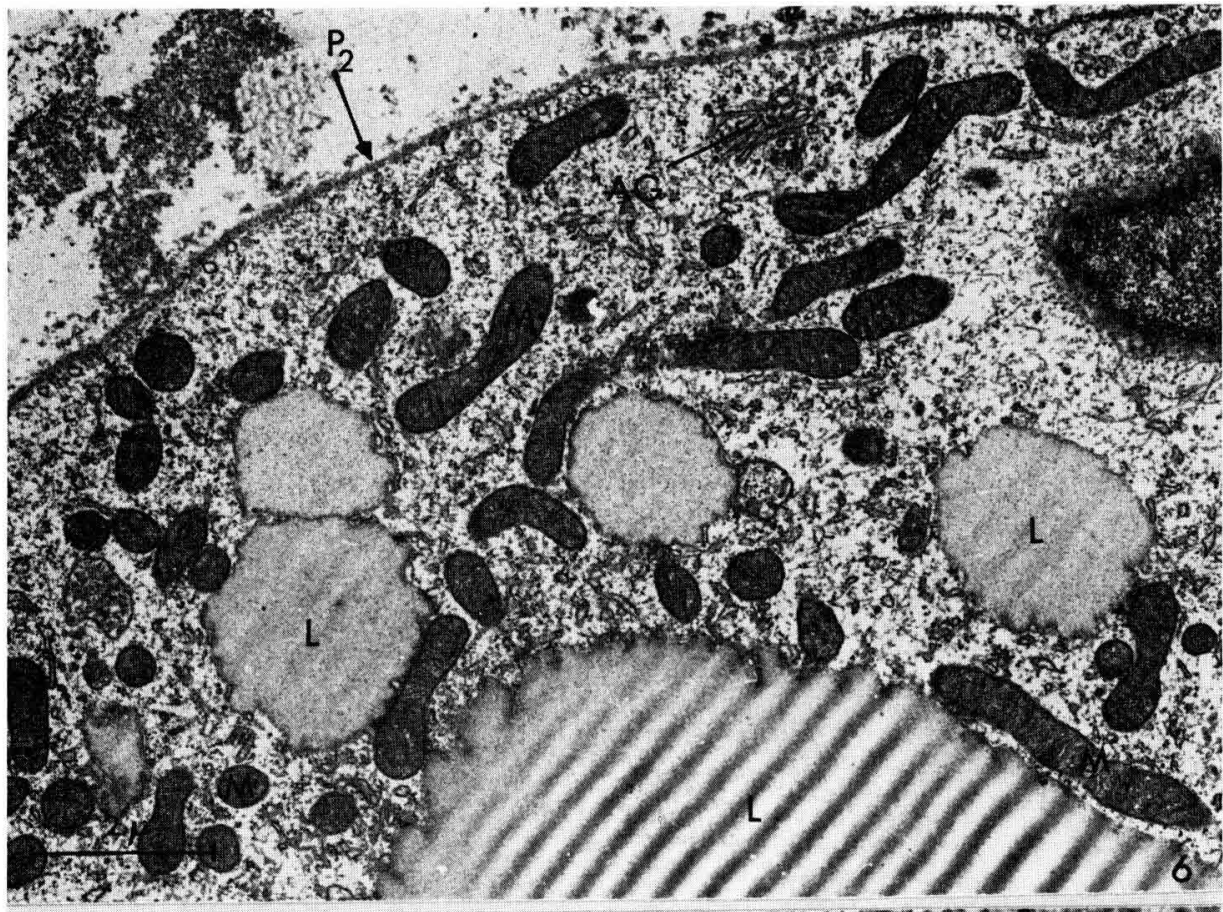
p a

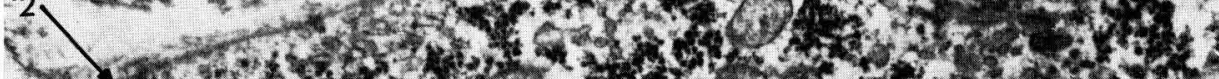

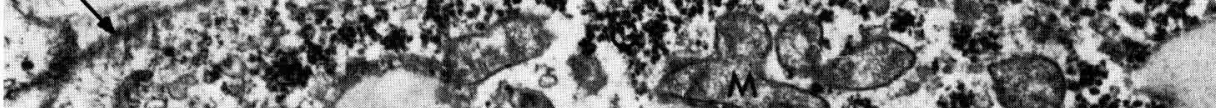

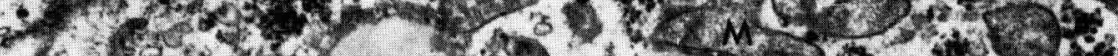

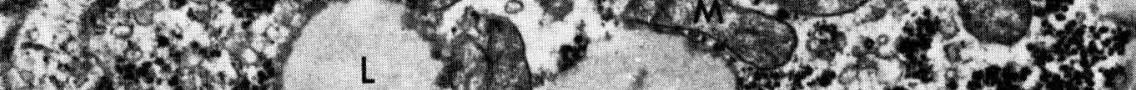

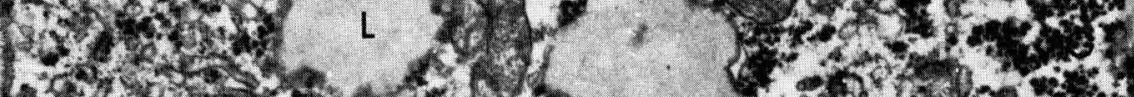

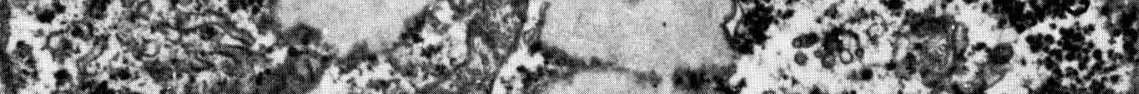

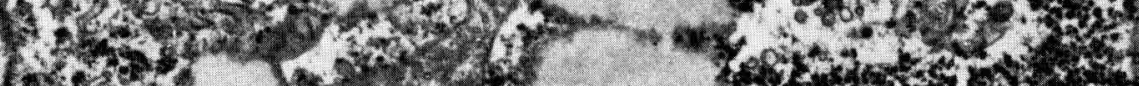

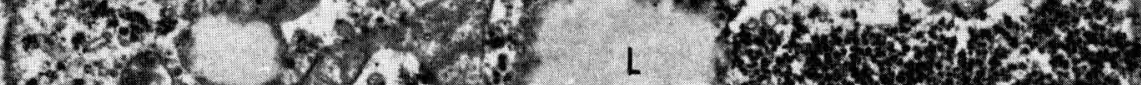

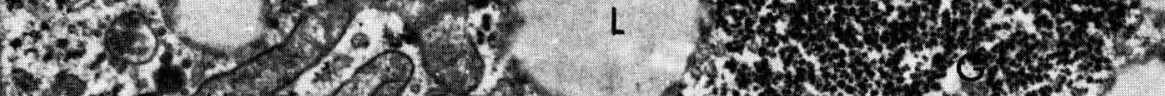

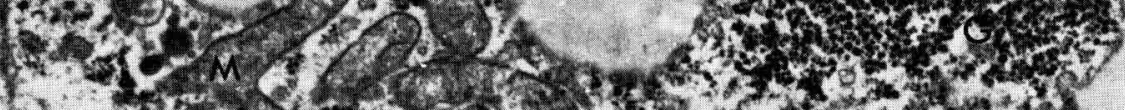

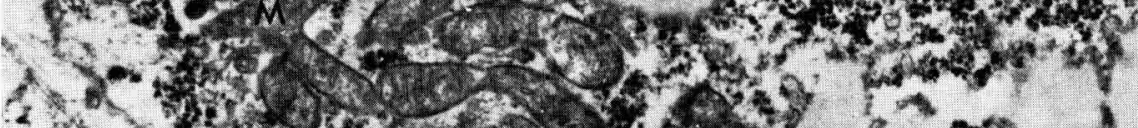
H

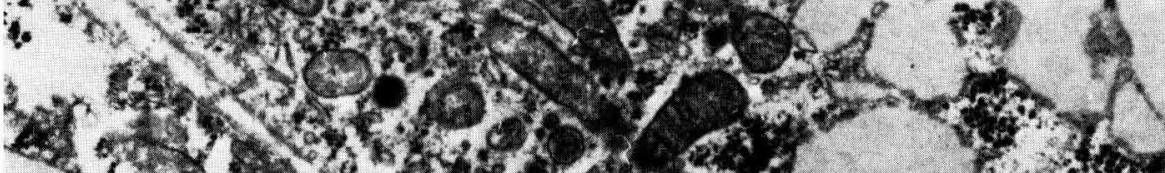




\section{PLANCHE VI}

FIG. 8

Partie de deux préadipocytes adjacents $P_{2}$ au stade de l'apparition des premières inclusions lipidiques; les fragments de reticulum en partie lisse REL et en partie rugueux RER sont abondants ; la matrice fondamentale cytoplasmique contient de nombreux ribosomes libres; la membrane plasmique MP est, sur certaines parties du pourtour, bien conservée et sur d'autres entremêlée avec la lame basale $B$, dont l'aspect est également variable $(\times 20.000)$.

\section{FrG. 9}

Vue partielle de deux adipocytes $A$ et $A_{1}$ adjacents, reliés par des fibres conjonctives $F$ de fort diamètre. Les mitochondries $M$ de l'anneau périphérique de l'adipocyte $\mathrm{A}_{1}$ sont à différents stades de dégradation. La membrane plasmique de cette partie des deux adipocytes n'est pas apparente et on observe à ce niveau de nombreuses vésicules $\mathrm{V}$; la lame basale ne se distingue pas $(\times 45.000)$. 


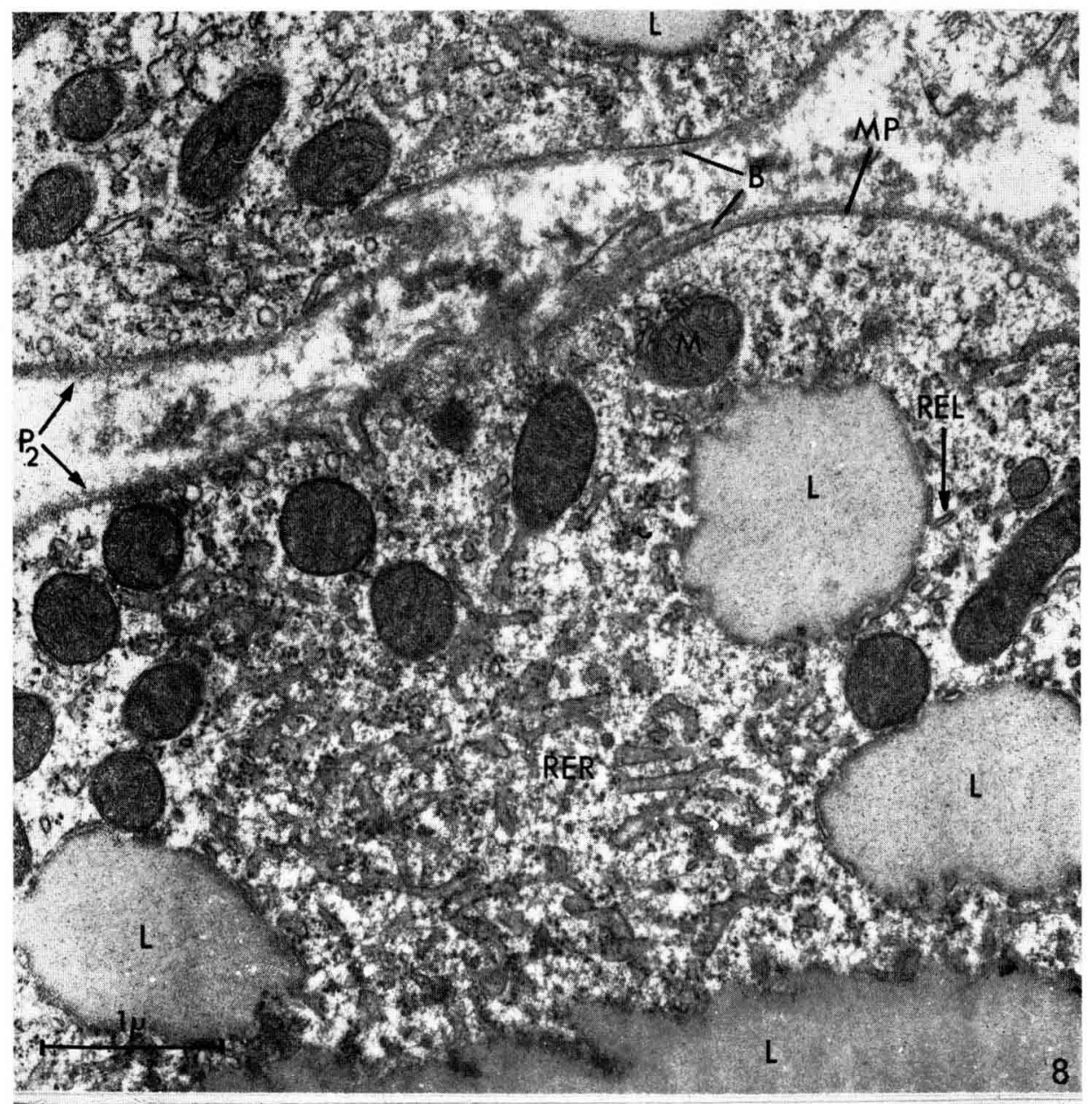

A 


\section{PLANCHE VII}

FIG. 10

Aspect des adipocytes $\mathrm{A}$ au stade avancé de leur maturation : l'anneau périphérique AP est très réduit ; le préadipocyte $P_{1}$ est situé entre les adipocytes et le capillaire sanguin $\mathrm{C}$; lipides, L $(\times 4.500)$. 


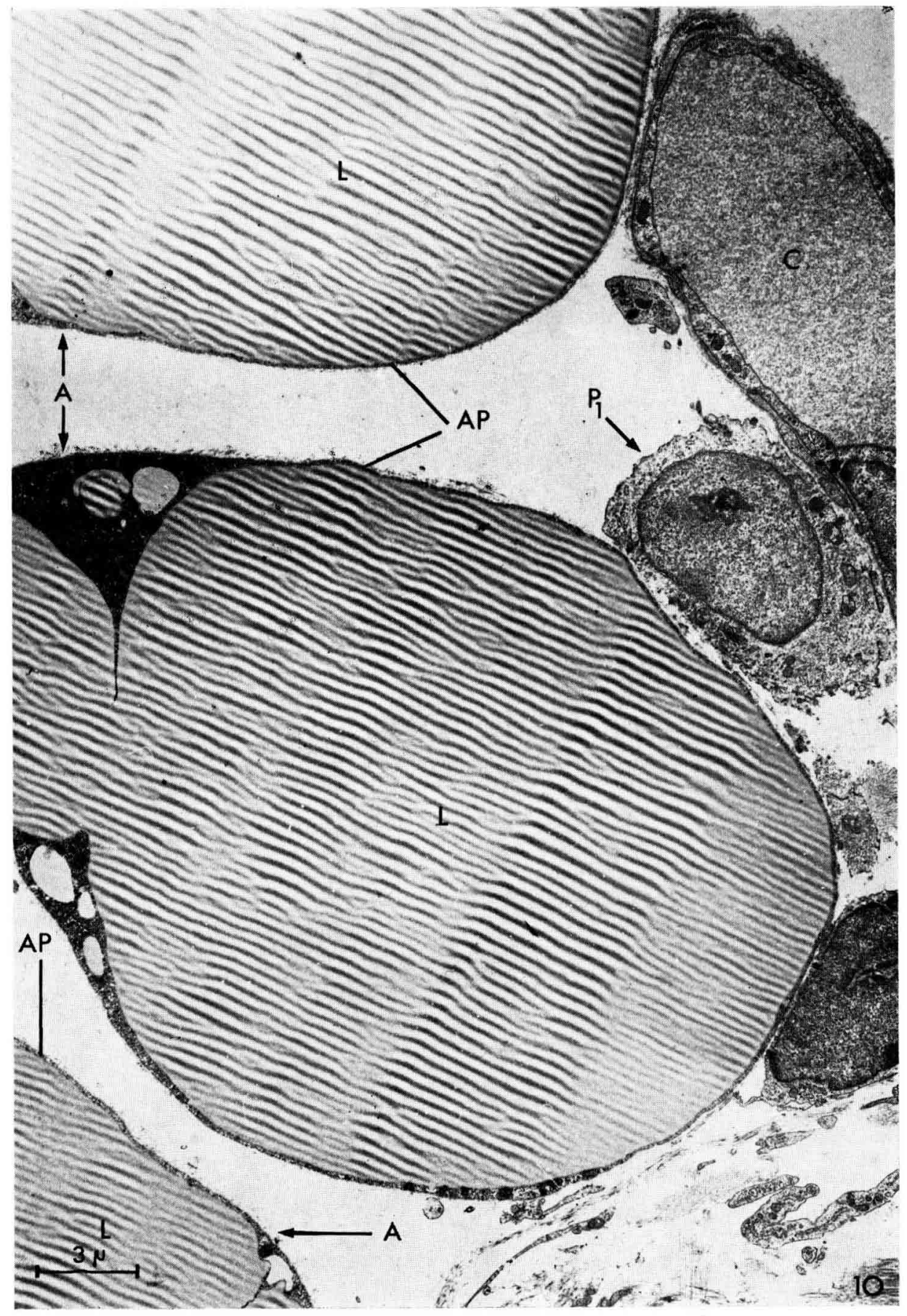

N. VODOVAR et coll. 


\title{
PLANCHE VIII
}

\author{
FIG. 11
}

L'anneau périphérique AP de l'adipocyte A est relativement important mais pratiquement dépourvu d'organites cellulaires ; la matrice fondamentale du cytoplasme CY est peu contrastée ; la membrane plasmique MP, contenant de nombreuses microinvaginations VP, est relativement bien conservée ainsi que la lame basale $B$; capillaire sanguin $C(\times 20.000)$.

FIG. 12

Vue partielle de trois adipocytes $A$ dont l'anneau périphérique $\mathrm{AP}$, bien défini, est très réduit et sans organites cellulaires ; préadipocyte $P_{1}$ placé entre adipocyte et capillaire sanguin $C(\times 6.000)$. 

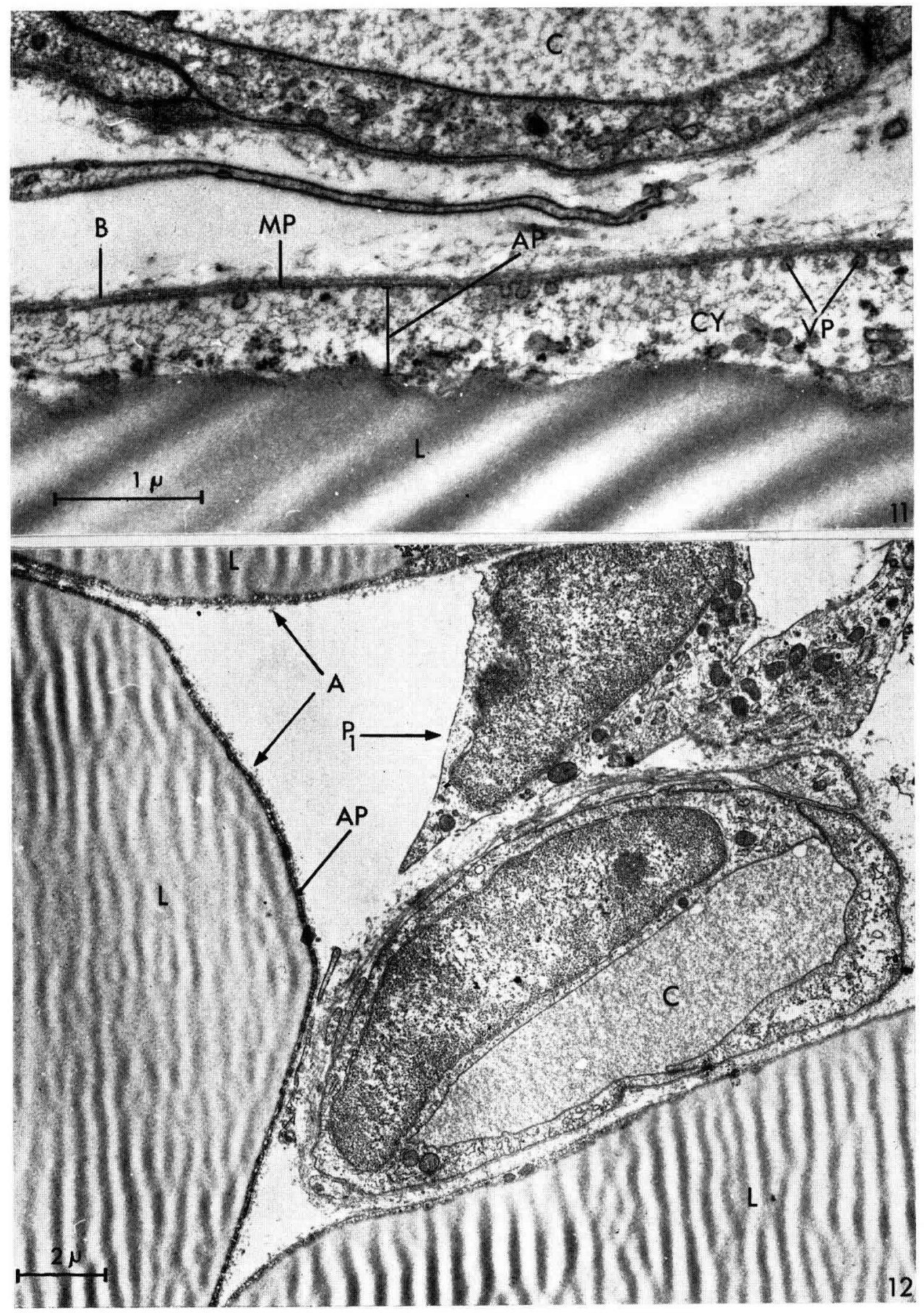

N. VODOVAR et coll. 


\section{PLANCHE IX}

FIG. 13

L'anneau périphérique AP, d'une partie de l'adipocyte A, sans organites cytoplasmiques, est au stade de la dégradation $(\times 45.000)$.

\section{FIG. 14}

A la périphérie de la masse lipidique $L$ de l'adipocyte $A$ l'anneau périphérique AP est entièrement dégradé $(\times 45.000)$. 


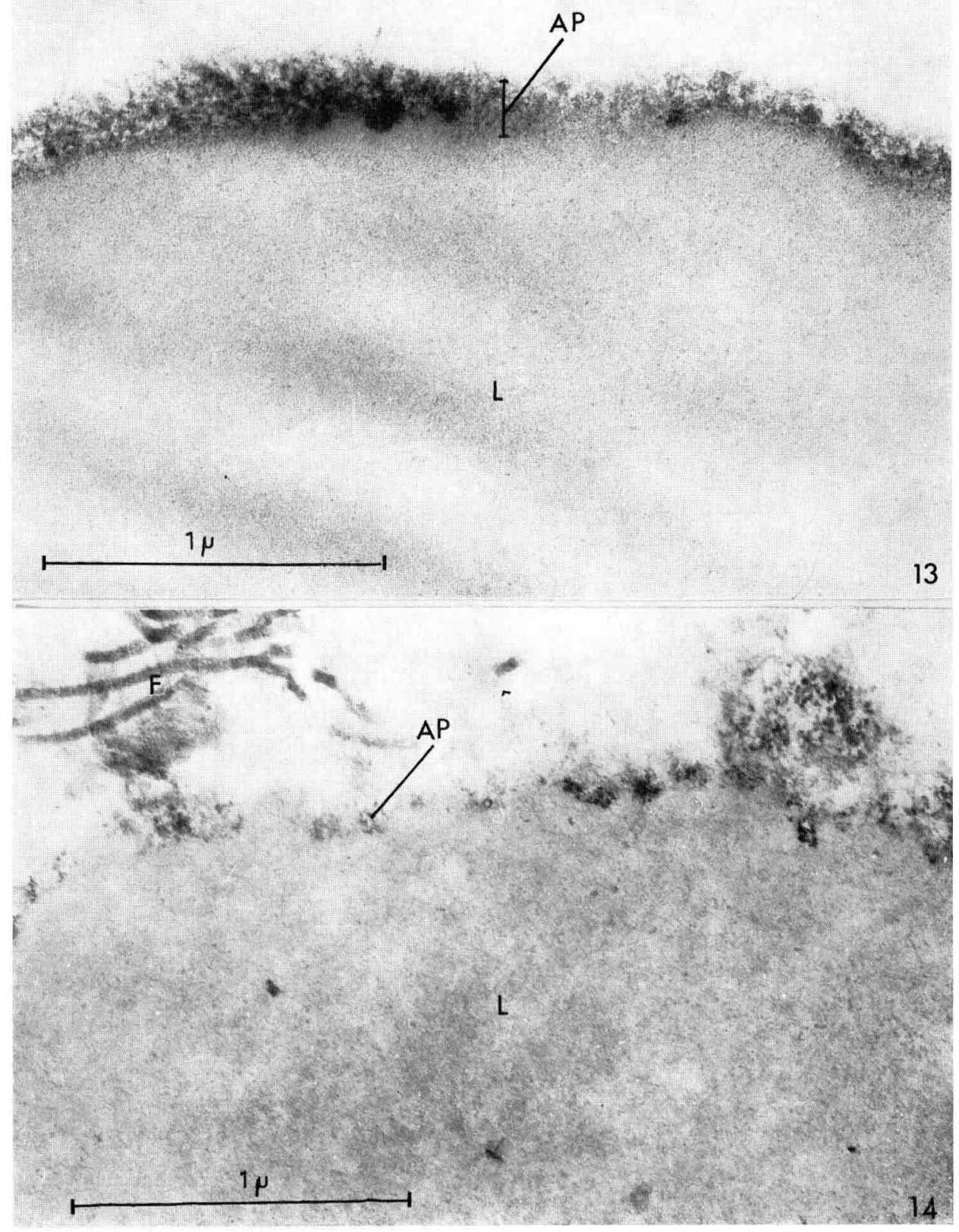

N. VODOVAR et coll. 